TITLE:

\title{
Analysis of Internet topology with three-level components model
}

$\operatorname{AUTHOR}(S)$ :

Ida, Takanori

\section{CITATION:}

Ida, Takanori. Analysis of Internet topology with three-level components model. 京都大学 大学院経済学研究科Working Paper 2003, 67

ISSUE DATE:

2003-01

URL:

http://hdl.handle.net/2433/37946

RIGHT: 


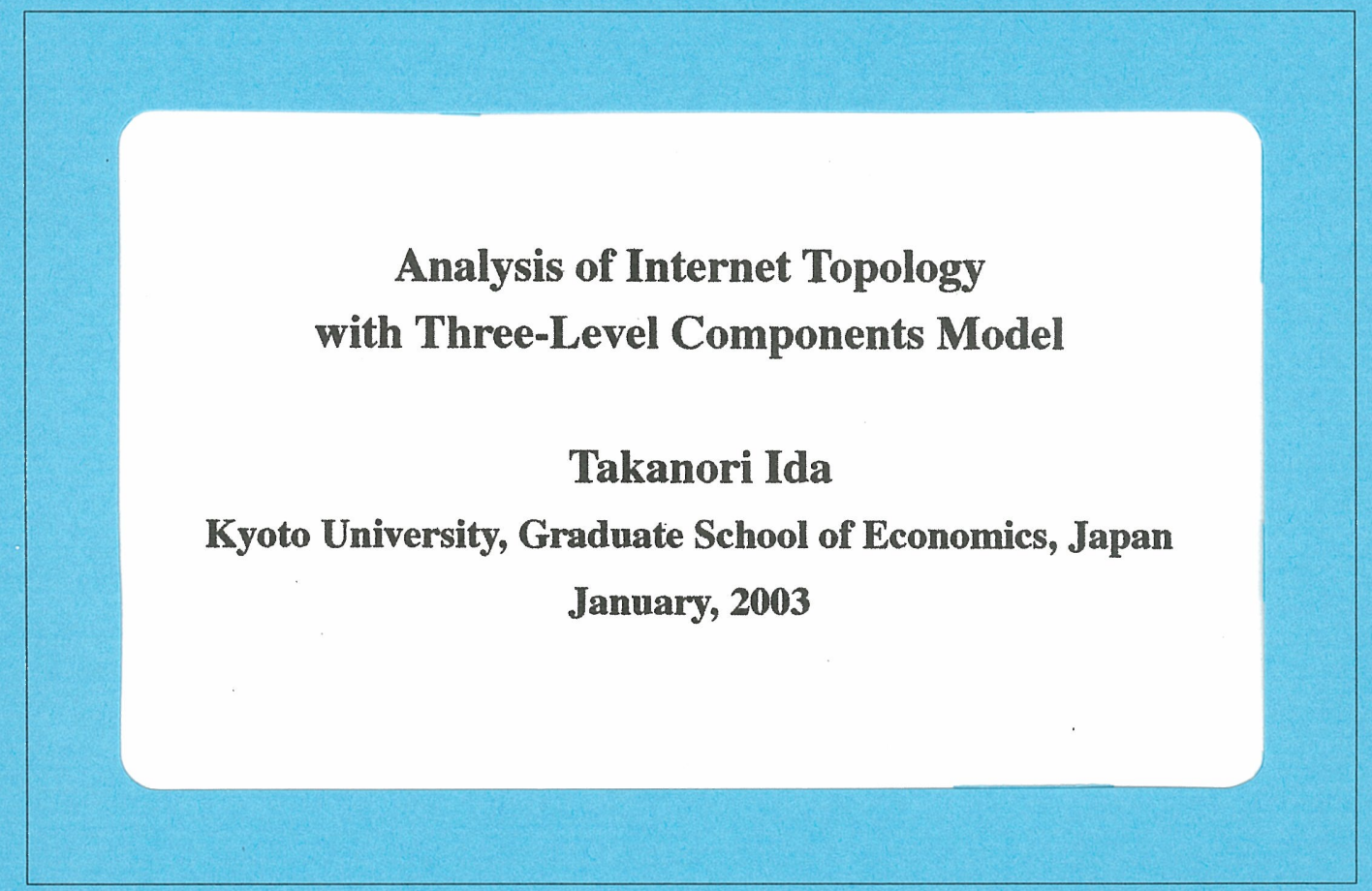

Graduate School of Economics

Faculty of Economics

Kyoto University

Kyoto, 606-8501 JAPAN 


\section{Analysis of Internet Topology with Three-Level Components Model}

\section{Takanori Ida}

Kyoto University, Graduate School of Economics, Japan January, 2003 


\title{
Analysis of Internet Topology with Three-Level Components Model
}

\author{
Takanori Ida \\ Faculty of Economics, Kyoto University, Associate Professor, Japan
}

\begin{abstract}
The vertical structure of the Internet can be considered as being made up of three-level components: backbone-level interconnection, mid-level transit, and locallevel access. Furthermore, the connection of networks can be classified into two types: one-way and two-way connections. This paper will analyze one-way and two-way connections and attempt to integrate them with the three-level components model. Three main conclusions will be obtained: first, two-way connection is more socially desirable than one-way connection; second, the cross entry of vertical integrators is more socially desirable than no entry and single entry; third, the local structure of oneway connection and the global structure of two-way connection should be determined at the same time, and, if any, the local bottleneck of one-way connection should be determined afterward rather than beforehand.
\end{abstract}

JEL Classification: L13, L51, L86

Keywords: One-way, Two-way, Component, Network, Internet

\section{Address:}

Takanori Ida

Faculty of Economics, Kyoto University, Yoshida, Sakyo, Kyoto 606-8501, Japan

Tel\&Fax: +81- 75-753-3477

E-mail:ida@econ.kyoto-u.ac.jp 


\section{Analysis of Internet Topology with Three-Level Components Model}

\section{Introduction}

One of the current problems which economics is facing is how to analyze the rapidly developing Internet. In the 1990 s, the Internet became a driving force for the growth of the world economy, and the theory of the 'New Economy' was quite popular. This paper tries to propose a framework for analyzing the industrial structure of the Internet. The connection of the Internet can be broken down into three-level components: backbone interconnection, intermediate conveyance, and local access. In addition to this, there are two kinds of connections: one-way connection and two-way connection. This paper will analyze one-way and two-way connections and attempt to integrate them with the three-level components model.

It will be helpful to explain at this point the key elements on which this paper depends. One-way connection is the network structure where one firm needs access to another but the reverse does not hold ${ }^{1}$. One example is: some Internet Service Providers (ISPs) provide access services to end-users in a retail market and at the same time serve as Internet Backbone Providers (IBPs) that provide transit services to ISPs in a wholesale market, while other ISPs that do not serve as IBPs have to buy transit

\footnotetext{
${ }^{1}$ See Laffont and Tirole, 2000, p.6. Also see the following for details of the one-way connection model: Armstrong, Doyle and Vickers (1996), Baumol and Sidak (1994), Laffont and Tirole (1994).
} 
services from IBPs to provide final services to customers. On the other hand, two-way connection demonstrates that customers communicating with each other belong to two different local networks and each carrier must buy termination access from the other network ${ }^{2}$. One example is: IBPs have to interconnect at a point of interconnection so that end-users on each network can exchange information ${ }^{3}$.

It will be useful here to adopt a 'components model' in order to consider oneway and two-way connections respectively. It was Matutes and Regibeau (1988) and Economides (1989) who introduced the components model. The components model analyzes how complementary components are combined to produce a valuable system ${ }^{4}$. For example, a computer itself will not be of any use to consumers without a complementary monitor. That is to say, the computer system is composed of a computer and monitor.

The paper consists of the following four sections. After providing a preliminary discussion, Section 2 compares one-way and two-way connections by using the two-level components model. The main conclusion is that two-way connection is

\footnotetext{
${ }^{2}$ See Laffont and Tirole, 2000, p.8. Also see the following for details of the two-way connection model: Armstrong (1998), Laffont, Ray and Tirole (1998), Giovannetti (2002),

${ }^{3}$ In the model analysis below, we will extend the definition of two-way connection to include one where customers can choose a component of services from multiple companies.

${ }^{4}$ See Shy, 2001, p.36. Also see the following for details of the components model: Economides and Salop (1992), Matutes and Regibeau (1992).
} 
more socially desirable than one-way connection in that the total output of two-way connection is larger than that of one-way connection. This is, first, because of the internalization of vertical externalities and, second, because of the action of the horizontal substitution effect.

Next, Section 3 tries to integrate one-way and two-way connections by using the three-level components model. There are two problems to be examined, which are actual problems especially in Japan as we see in Section 1.1. One problem is to analyze the social effect of the entry of vertical integrators into different areas. Because most of ISPs have been integrated forward into IBPs and because the Internet industry is still vertically and horizontally oligopolistic, it is interesting to compare three cases: no entry, single entry, and cross entry. The main results are: first, cross entry is more socially desirable than no entry in that the total output of the cross entry model is larger than that of the no entry model; second, cross entry is more socially desirable than single entry in that the total output of the cross entry model is larger than that of the single entry model.

The other problem is to analyze the social effect of the timing of the games. Since the network structure of local access is in the form of one-way connection while that of the global interconnection, or 'peering', takes the form of two-way connection, it is interesting to ask whether both should be determined at the same time, or, if any, which connection should be determined beforehand. The main results are: first, the 
local structure of one-way connection and the global structure of two-way connection should be determined at the same time in that the total output of the simultaneous model is larger than those of the sequential models; second, the local bottleneck of one-way connection should be determined afterward rather than beforehand, or in other words the global interconnection of two-way connection should be decided beforehand rather than afterward in that the total output of the sequential model where two-way connection is determined first is larger than that of the sequential model where one-way connection is determined first. Section 4 draws a conclusion.

\subsection{A preliminary discussion}

At this point, we will comment on the industrial structure of the Internet, in particular that of Japan. The Internet is the global aggregate of various, large or small, local networks: The Internet structure can be summarized simply as the three-levels: the bottom-level local access, the regional or mid-level conveyance, and the backbonelevel interconnection ${ }^{5}$. There are two principal types of Internet providers. One is ISP, which provides access services for end-users at a retail level, while the other is IBP, which provides transit services for ISP at a wholesale level. Therefore, an ISP has to connect to an IBP so that it connects to another ISP. The IBP 'peers' with other IBPs at network access points (NAPs) ${ }^{6}$. There is a wide array of ISP ranging from a mom-

\footnotetext{
${ }^{5}$ See MacKie-Mason and Varian, 1997, p.30.

${ }^{6}$ See McKnight and Leida, 2001, p.195.
} 
and-pop operation offering services to a small number of subscribers in a specific location to a national operator that offers access across the whole country. Since the cost of becoming a local ISP is very low, competition among ISPs is extremely intense, and a significant number of entries and exits of ISPs occur. Besides, the IBP that provides backbone services at the wholesale level can be considered as an upstream supplier from the viewpoint of an ISP. Most ISPs have been integrated forward into IBPs. Fig. 1 illustrates the discussion above.

$<$ Fig. 1 >

The industrial structure of the Internet can be summarized as follows when we focus on the vertical perspectives ${ }^{7}$. (1) Incentives to vertically integrate on the Internet are still strong; particularly, downstream integration is more likely than upstream. Thus, the first problem we would like to examine is to analyze the social effect of vertical integration into different areas. (2) The viability of the wholesale market is enhanced; particularly, the incumbent facilities-based providers will integrate into the developing Internet services. Thus, the second problem we would like to examine is to analyze which should precede, the local one-way connection or the global two-way connection. To understand these features of the industrial structure of the Internet, it seems helpful to use the components model approach because we came to choose

\footnotetext{
${ }^{7}$ See Lehr, 2001, p. 109.
} 
network components freely as a result of 'unbundling' policies in telecommunications.

Here we will briefly comment on the current situation of Japanese Internet providers $^{8}$. First, let us begin with the various types of Internet providers. Most Internet providers used to be personal-computer-communication companies that did not have their own telecommunications facilities. However, telecommunications companies that have their own telecommunications facilities have recently increased their market share. Fig. 2 illustrates the market share of Japanese Internet subscribers from 1998 to 2000 according to the type of provider'. We can understand that telecommunications-type providers have captured a significant proportion of the customers of personal-computer-communication companies. This is because price competition among the Internet providers has become intense and conventional personal-computer-communications companies have lost price competitiveness against the large-scale and vertically integrated telecommunications companies ${ }^{1011}$.

\footnotetext{
${ }^{8}$ The figures used here are taken from "The White Paper of the Internet" by the Impress Co., Japan. However, we have to be cautious about the result because the figures are largely based on the method by which the data is extracted.

${ }^{9}$ It should be noted that since the investigation admits of multiple answers the sum of market shares exceeds $100 \%$.

${ }^{10}$ One reason why the market share of telephone companies has increased rapidly in recent years is an indirect or direct effect of the sudden spread of the Internet service through cellular phones, and in particular the success of 'i-mode' of NTT DoCoMo is quite well-known.

${ }^{11}$ In addition, broadband services such as ADSL and FTTH have been operating since 2000, and a competitive-power gap between a company with telecommunications facilities and one without continues to widen.
} 


\section{$<$ Fig. 2>}

In addition, the breakdown of the subscribers' share of telecommunicationstype providers is shown in Fig. 3. Here we can see that the market share of the NTT group is high enough to be almost equal to that of all other common carriers. This is because the brand image of the biggest telephone company in the world has a positive effect even as an Internet provider. On the other hand, the foreign-capital providers have been gradually increasing the number of subscribers as a result of 'cross-entry'. This tendency will continue in the future because Japan Telecom merged with a big British cellular phone company, Vodaphone. It follows from the above evidence that the Japanese Internet industry is still highly oligopolistic and vertical integrators have the competitive edge.

$<$ Fig. 3>

\section{The analysis of one-way and two-way connections}

In this section, we will compare one-way and two-way connections with the two-level components model, before going onto the three-level components model.

\subsection{The basic setup of the two-level components model}


This section will explain the basic setup of the two-level components model. We assume at this point that there are two levels of 'components', $A$ and B. For example, component A means an access service from ISP to end-users while component B means a transit service between IBP and ISP. It is also assumed that each component has two types, namely $A_{1} / A_{2}$ and $B_{1} / B_{2}$. We call the combination of components a 'system'. Systems are $A_{1} B_{1}, A_{1} B_{2}, A_{2} B_{1}$, and $A_{2} B_{2}$. Defining the prices of components $A_{i}$ and $B_{j}$ are $P_{i}$ and $Q_{j}$ respectively, the price of system $A_{i} B_{j}, S_{i j}$, can be represented as the sum of the prices of components:

$$
S_{i j}=P_{i}+Q_{j} ; i, j=1,2 \text {. }
$$

Let us assume linear demand functions of systems $A_{i} B_{j}, D_{i j}$, for the sake of simplicity, following the previous research into components model. The own effect of price to demand is represented by coefficient $b$, the cross effects are represented by coefficients $c, d$, and e. Accordingly the demand functions of systems are given as follows:

$$
\begin{aligned}
& \mathrm{D}_{11}=\mathrm{a}-\mathrm{bS} \mathrm{S}_{11}+\mathrm{cS} \mathrm{S}_{12}+\mathrm{dS} \mathrm{S}_{21}+\mathrm{eS}_{22} \\
& D_{12}=a-b S_{12}+c S_{11}+d S_{22}+e S_{21} \\
& \mathrm{D}_{21}=\mathrm{a}-\mathrm{bS}_{21}+\mathrm{cS}_{22}+\mathrm{dS}_{11}+\mathrm{eS}_{12} \\
& D_{22}=a-b S_{22}+c S_{21}+d S_{12}+e S_{11} \text {. }
\end{aligned}
$$


The demand functions of components are given as follows: for example, the demand of component $A_{1}, D_{A 1}$, is represented as the sum of the demands of systems $A_{1} B_{1}$ and $A_{1} B_{2}, D_{11}$ and $D_{12}$

$$
\begin{aligned}
& \mathrm{D}_{\mathrm{A} 1}=\mathrm{D}_{11}+\mathrm{D}_{12} \\
& \mathrm{D}_{\mathrm{A} 2}=\mathrm{D}_{21}+\mathrm{D}_{22} \\
& \mathrm{D}_{\mathrm{B} 1}=\mathrm{D}_{11}+\mathrm{D}_{21} \\
& \mathrm{D}_{\mathrm{B} 2}=\mathrm{D}_{12}+\mathrm{D}_{22}
\end{aligned}
$$

At this point, we need further assumptions to simplify the analysis:

A1. The constant cross-effects of prices: $c=d=e$.

A2. The non-negative equilibrium prices and quantities: $b>3 c>0$.

A3. The zero marginal costs of production.

A4. Furthermore, all parameters are normalized by $b: b=1$.

\subsection{The one-way connection model}

One-way connection (abbreviated as 1w) demonstrates the case where two types of firms exist: one is a dominant firm that monopolizes one level of component and the other is a partial entrant. The dominant firm provides $A_{1} / B_{1} / B_{2}$ whereas the 
partial entrant provides only $A_{2}$. The possible interpretation is that the dominant firm is an IBP that integrates an ISP and the partial entrant is a disintegrated ISP. Customers can choose component A from two providers but component B from only the dominant provider. Therefore, there are four kinds of systems as final products, $A_{1} B_{1}$, $A_{1} B_{2}, A_{2} B_{1}$, and $A_{2} B_{2}$; firm 1 sets the prices of components $A_{1} / B_{1} / B_{2}$, and firm 2 sets the price of component $\mathrm{A}_{2}$. Fig. 4 (a) illustrates the one-way connection model as explained above.

$<$ Fig. 4>

The firms' profit functions $\Pi_{1}$ and $\Pi_{2}$ are given as follows:

$$
\begin{aligned}
& \Pi_{1}=\mathrm{P}_{1} \mathrm{D}_{\mathrm{A} 1}+\mathrm{Q}_{1} \mathrm{D}_{\mathrm{B} 1}+\mathrm{Q}_{2} \mathrm{D}_{\mathrm{B} 2} \\
& \Pi_{2}=\mathrm{P}_{2} \mathrm{D}_{\mathrm{A} 2}
\end{aligned}
$$

The first-order conditions of profit maximization can be obtained by differentiating profits functions $\Pi_{1}$ and $\Pi_{2}$ from prices $P_{1} / Q_{1} / Q_{2}$ and $P_{2}$. The equilibrium prices and quantities are shown in Table 1.

$<$ Table 1>

\subsection{The two-way connection model}


Next, we move on to explain the two-way connection model (abbreviated as 2w). Two-way connection means that there is no dominant carrier and that firm 1 provides $A_{1} / B_{1}$ while firm 2 provides $A_{2} / B_{2}$. For example, it can be thought that component $\mathrm{A}$ is a transit service between IBP and ISP and component $\mathrm{B}$ is the interconnection service between IBPs. Each component has two types, $A_{1} / A_{2}$ and $B_{1} / B_{2}$. Component $B$ is compatible with two providers, and $B_{1}$ can be combined with $A_{2}$ as well as $A_{1}$ to produce the systems $A_{1} B_{1}$ and $A_{2} B_{1}$ respectively. The same thing can be said of $B_{2}$. We have here four kinds of systems as final products, $A_{1} B_{1}, A_{1} B_{2}$, $A_{2} B_{1}$, and $A_{2} B_{2}$. Firm 1 sets the prices of $A_{1} / B_{1}$ and firm 2 sets the prices of $A_{2} / B_{2}$. Fig. 4 (b) illustrates the two-way connection model as explained above.

The firms' profit functions $\Pi_{1}$ and $\Pi_{2}$ are given as follows:

$$
\begin{aligned}
& \Pi_{1}=P_{1} D_{A 1}+Q_{1} D_{B 1} \\
& \Pi_{2}=P_{2} D_{A 2}+Q_{2} D_{B 2}
\end{aligned}
$$

The first-order conditions of profit maximization can be obtained by differentiating profit functions $\Pi_{1}$ and $\Pi_{2}$ from prices $P_{1} / Q_{1}$ and $Q_{2} / P_{2}$. The equilibrium prices and quantities are shown in Table 2.

$<$ Table 2> 


\subsection{The result of the analysis of one-way and two-way connections}

Now let us investigate the result of one-way and two-way connections. The main conclusions obtained from Tables 1 and 2 can be summarized as the following lemmas and proposition ${ }^{12}$.

Lemma 1.1 (The components' prices of $1 \mathrm{w}$ ): $\mathrm{P}_{1}{ }^{1 \mathrm{w}}<\mathrm{P}_{2}{ }^{1 \mathrm{w}}, \mathrm{Q}_{1}{ }^{1 \mathrm{w}}=\mathrm{Q}_{2}{ }^{1 \mathrm{w}}$.

Lemma 1.2 (The components' prices of $2 \mathrm{w}$ ): $\mathrm{P}_{1}{ }^{2 \mathrm{w}}=\mathrm{P}_{2}{ }^{2 \mathrm{w}}=\mathrm{Q}_{1}{ }^{2 \mathrm{w}}=\mathrm{Q}_{2}{ }^{2 \mathrm{w}}$.

Lemma 1.3 (The comparison of components' prices between $1 \mathrm{w}$ and $2 \mathrm{w}$ ):

$$
\mathrm{P}_{1}{ }^{1 \mathrm{w}}<\mathrm{P}_{1}{ }^{2 \mathrm{w}}, \mathrm{P}_{2}{ }^{1 \mathrm{w}} \geq(<) \mathrm{P}_{2}{ }^{2 \mathrm{w}} \text { iff } \quad \mathrm{c} \leq(>) 0.091, \mathrm{Q}_{1}{ }^{1 \mathrm{w}}=\mathrm{Q}_{2}{ }^{1 \mathrm{w}}>\mathrm{Q}_{1}{ }^{2 \mathrm{w}}=\mathrm{Q}_{2}{ }^{2 \mathrm{w}} \text {. }
$$

Lemma 1.1 examines the components' prices of one-way connection (1w). Since the price of $A_{1}$ that a dominant provider sets is lower than that of $A_{2}$ that an entrant sets, the system demand of the dominant provider is larger than that of the entrant. This result demonstrates the advantage of the dominant provider because it can set the price of vertically integrated components taking system demands into consideration. Lemma 1.2 examines the components' prices of two-way connection (2w). Since two symmetric vertical integrators compete, the prices of all components that they set are identical. Therefore, all prices of systems are also identical, and

\footnotetext{
${ }^{12}$ We can obtain all lemmas and propositions by direct calculation under the parameter conditions such as $a>0$ and $1 / 3>c>0$. The proof note will be available on request.
} 
system demands are symmetric. This is because neither has an advantage in competition. Lemma 1.3 compares the components' prices of one-way and two-way connections. It is important to note that in the one-way connection model, the price of component $\mathrm{B}$ is relatively higher because competition does not work at this level; by contrast, in the two-way connection model, the price of component B is relatively lower because competition works at this level.

Proposition 1 (The comparison of total outputs between $1 \mathrm{w}$ and $2 \mathrm{w}$ ): $\Sigma \Sigma \mathrm{D}^{1 \mathrm{w}}<\Sigma \Sigma \mathrm{D}^{2 \mathrm{w}}$

Proposition 1 compares the total outputs between the models of one-way (1w) and two-way ( 2 w) connections ${ }^{13}$. Two-way connection is more socially desirable than one-way connection in that the total output of two-way connection is larger than that of one-way connection. Why is two-way connection more socially desirable than oneway connection? There are two reasons for this. One is the internalization of vertical externalities. Vertical integrators can set prices considering the demands of systems instead of components. In other words, two-way connection can avoid the problem of double marginalization that increases the prices of systems and decreases system demands. The other is the action of the horizontal substitution effect. That is to say,

\footnotetext{
${ }^{13}$ Since prices are higher than marginal costs, outputs are considered socially too few. Accordingly, we can regard the total output of systems as an index indicating social welfare. It is thought that the more the total output, the higher the social welfare.
} 
since there is no firm that monopolizes components, the price competition in terms of systems works effectively and system demands are increased.

\section{An attempt to integrate one-way and two-way connections}

In this section, we will attempt to integrate one-way and two-way connections with the three-level components model, which no studies have ever tried. The integrated models of one-way and two-way connections are classified as either simultaneous models or sequential models. We will analyze each type in turn.

\subsection{The basic setup of the three-level components model}

This section will explain the basic setup of the three-level components model. The actual topology of the Internet seems to be an integrated structure of the local oneway connection and the global two-way connection. Suppose that there are three levels of components, $\mathrm{A}, \mathrm{B}$, and $\mathrm{C}$. For example, component $\mathrm{A}$ is an access service from ISP to end-users, component B is a transit service between IBP and ISP, and component $\mathrm{C}$ is an interconnection service between IBPs. Each component has two types, $i=1,2$, given that there are two areas, $j=x, y$. On the one hand, a dominant firm $1 \mathrm{X}$ provides three components, $\mathrm{A}_{1 \mathrm{x}} / \mathrm{B}_{1 \mathrm{x}} / \mathrm{C}_{1 \mathrm{x}}$, and an entrant $2 \mathrm{X}$ provides one component $A_{2 x^{*}}$ On the other hand, another dominant firm $1 Y$ provides three components, $\mathrm{A}_{1 \mathrm{y}} / \mathrm{B}_{1 \mathrm{y}} / \mathrm{C}_{1 \mathrm{y}}$, and another entrant $2 \mathrm{Y}$ provides one component $\mathrm{A}_{2 \mathrm{y}}$. Fig. 4 (c) 
summarizes the attempt to integrate one-way and two-way connections as explained above.

We can formulate two kinds of models to analyze the integrated model of oneway and two-way connections. The first formulation is the simultaneous model where one-way and two-way connections are determined at the same time. Furthermore, we will develop this simultaneous model in the following two ways: first, both dominant providers try to integrate entrants operating in different areas; second, only one dominant provider tries to integrate an entrant operating in a different area. The former is called 'cross entry' while the latter 'single entry'. The second formulation is the sequential model where one-way and two-way connections are determined in turn. There are two kinds of sequential models, One is the model in which one-way connection is determined first and two-way connection second. The other is the model in which two-way connection is determined first and one-way connection second. In the former model the local network structure precedes the global network structure, while in the latter model the global network structure precedes the local network structure.

We assume, as stated earlier, that there are three levels of components, A, B, and $\mathrm{C}$, and there are two areas, $\mathrm{x}$ and $\mathrm{y}$. In each area, there are two kinds of each component, $A_{i j}, B_{k l}, C_{m n}(i, k, m=1,2 ; j, 1, n=x, y)$. We make an assumption that endusers living in area $x$ cannot choose components $A_{i y}$ and $B_{k y}$ provided in area y because 
of regional restrictions; the converse holds for end-users living in area y. For the sake of simplicity, we assume that $B_{11}=B_{21}$ and $C_{1 n}=C_{2 n}$. Systems are $A_{1 x} B_{1 x} C_{1 x}, A_{1 x} B_{1 x} C_{1 y}$, $A_{2 x} B_{1 x} C_{1 x}, A_{2 x} B_{1 x} C_{1 y}, A_{1 y} B_{1 y} C_{1 y}, A_{1 y} B_{1 y} C_{1 x}, A_{2 y} B_{1 y} C_{1 y}$, and $A_{2 y} B_{1 y} C_{1 x}$. Defining the prices of components $A_{i j}, B_{k l}$, and $C_{m n}$ are $P_{i j}, Q_{k d}$, and $R_{m n}$ respectively, the prices of system $A_{i j} B_{k 1} C_{m n}, S_{i j k l m n}$, can be represented as the sum of the prices of the components:

$$
S_{i j k l m n}=P_{i j}+Q_{k l}+R_{m n}
$$

Let us assume again linear demand functions of systems $A_{i j} B_{k l} C_{m n}, D_{i j k l m n}$, for the sake of simplicity. The own effect of price to demand is represented by coefficient b, the cross effects are represented by coefficients $c, d$, and e. The demand functions of systems are given as follows:

$$
\begin{aligned}
& D_{1 x 1 x 1 x}=a-b S_{1 x 1 \times 1 x}+c S_{2 x 1 \times 1 x}+d S_{1 x 1 \times 1 y}+e S_{2 x 1 x 1 y} \\
& D_{1 \times 1 \times 1 y}=a-b S_{1 \times 1 \times 1 y}+c S_{1 \times 1 \times 1 x}+d S_{2 \times 1 \times 1 x}+e S_{2 x 1 \times 1 y} \\
& D_{2 \times 1 \times 1 x}=a-b S_{2 \times 1 \times 1 x}+c S_{1 \times 1 \times 1 x}+d S_{1 \times 1 \times 1 y}+e S_{2 x 1 \times 1 y} \\
& D_{2 x 1 \times 1 y}=a-b S_{2 x 1 \times 1 y}+c S_{1 \times 1 \times 1 x}+d S_{2 \times 1 \times 1 x}+e S_{1 \times 1 \times 1 y} \\
& \mathrm{D}_{1 \mathrm{y} 1 \mathrm{y} 1 \mathrm{y}}=\mathrm{a}-\mathrm{b} \mathrm{S}_{1 \mathrm{y} 1 \mathrm{y} 1 \mathrm{y}}+\mathrm{cS} \mathrm{S}_{1 \mathrm{y} 1 \mathrm{y} 1 \mathrm{x}}+\mathrm{d} \mathrm{S}_{2 \mathrm{y} 1 \mathrm{y} 1 \mathrm{x}}+\mathrm{e} \mathrm{S}_{2 \mathrm{y} 1 \mathrm{y} 1 \mathrm{y}} \\
& D_{1 y 1 y 1 x}=a-b S_{1 y 1 y 1 x}+c S_{2 y 1 y 1 x}+d S_{1 y 1 y 1 y}+e S_{2 y 1 y 1 y} \\
& D_{2 y 1 y 1 y}=a-b S_{2 y 1 y 1 y}+c S_{1 y 1 y 1 x}+d S_{2 y 1 y 1 x}+e S_{1 y 1 y 1 y}
\end{aligned}
$$

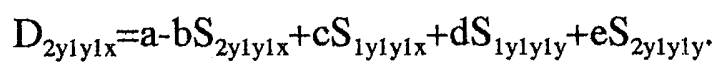


Demand functions of components are given as follows; for example, the demand of component $A_{1 x}, D_{A 1 x}$, is represented as the sum of the demands of systems $A_{1 x} B_{1 x} C_{1 x}$ and $A_{1 x} B_{1 x} C_{1 y}, D_{1 \times 1 \times 1 x}$ and $D_{1 x 1 x 1 y}$

$$
\begin{aligned}
& D_{A 1 x}=D_{1 \times 1 \times 1 x}+D_{1 x 1 \times 1 y} \\
& D_{A 2 x}=D_{2 x 1 \times 1 x}+D_{2 x 1 \times 1 y} \\
& D_{B 1 x}=D_{1 x 1 x 1 x}+D_{1 x 1 \times 1 y}+D_{2 x 1 \times 1 x}+D_{2 x 1 x 1 y} \\
& D_{C 1 x}=D_{1 x 1 x 1 x}+D_{2 x 1 \times 1 x}+D_{1 y 1 y 1 x}+D_{2 y 1 y 1 x} \\
& D_{A 1 y}=D_{1 y 1 y 1 y}+D_{1 y 1 y 1 x} \\
& D_{A 2 y}=D_{2 y 1 y 1 y}+D_{2 y 1 y 1 x} \\
& D_{B 1 y}=D_{1 y 1 y 1 y}+D_{1 y 1 y 1 x}+D_{2 y 1 y 1 y}+D_{2 y 1 y 1 x} \\
& D_{C 1 y}=D_{1 y 1 y 1 y}+D_{2 y 1 y 1 y}+D_{1 x 1 x 1 y}+D_{2 x 1 x 1 y}
\end{aligned}
$$

Here we make the same assumptions as those in the two-level components model, A1-A4, to simplify the analysis.

\subsection{The analysis of the simultaneous models of one/two-way connections}

In this section, the simultaneous model of one/two-way connections, ones with cross entry and with single entry will be investigated.

\subsubsection{The simultaneous model of one/two-way connections}


The simultaneous model of one/two-way connections (abbreviated as $1 / 2 \mathrm{w}$ ) means that firm $1 \mathrm{X}$ provides components $\mathrm{A}_{1 \mathrm{x}} / \mathrm{B}_{1 \mathrm{x}} / \mathrm{C}_{1 \mathrm{x}}$, and firm $2 \mathrm{X}$ provides only component $A_{2 x}$. Similarly, firm $1 Y$ provides components $A_{1 y} / B_{1 y} / C_{1 y}$, and firm $2 Y$ provides only component $A_{2 y}$.

The firms' profit functions $\Pi_{1 \mathrm{x}}, \Pi_{2 \mathrm{x}}, \Pi_{1 \mathrm{y}}$, and $\Pi_{2 \mathrm{y}}$ are given as follows:

$$
\begin{aligned}
& \Pi_{1 \mathrm{x}}=\mathrm{P}_{1 \mathrm{x}} \mathrm{D}_{\mathrm{A} 1 \mathrm{x}}+\mathrm{Q}_{1 \mathrm{x}} \mathrm{D}_{\mathrm{B} 1 \mathrm{x}}+\mathrm{R}_{1 \mathrm{x}} \mathrm{D}_{\mathrm{Clx}} \\
& \Pi_{2 \mathrm{x}}=\mathrm{P}_{2 \mathrm{x}} \mathrm{D}_{\mathrm{A} 2 \mathrm{x}} \\
& \Pi_{1 \mathrm{y}}=\mathrm{P}_{1 \mathrm{y}} \mathrm{D}_{\mathrm{A} 1 \mathrm{y}}+\mathrm{Q}_{1 \mathrm{y}} \mathrm{D}_{\mathrm{B} 1 \mathrm{y}}+\mathrm{R}_{1 \mathrm{y}} \mathrm{D}_{\mathrm{Cly}} \\
& \Pi_{2 \mathrm{y}}=\mathrm{P}_{2 \mathrm{y}} \mathrm{D}_{\mathrm{A} 2 \mathrm{y}} .
\end{aligned}
$$

The first-order conditions of profit maximization can be obtained by differentiating profit functions $\Pi_{1 x}, \Pi_{2 x}, \Pi_{1 y}$, and $\Pi_{2 y}$ from prices $P_{1 x} / Q_{1 x} / R_{1 x}, P_{2 x}$, $\mathrm{P}_{1 y} / \mathrm{Q}_{1 y} / \mathrm{R}_{1 \mathrm{y}}, \mathrm{P}_{2 \mathrm{y}^{*}}$. The equilibrium prices and quantities are shown in Table 3.

$<$ Table 3>

\subsubsection{The simultaneous model of one/two-way connections with cross entry}

The simultaneous model of one/two-way connections is now developed so 
that firm $1 X$ merges with firm $2 Y$ while firm $1 Y$ merges with firm $2 X$. The simultaneous model of one/two-way connections with cross entry (abbreviated as $1 / 2 \mathrm{w}+\mathrm{c}$ ) means that firm $1 \mathrm{X}$ provides components $\mathrm{A}_{1 \mathrm{x}} / \mathrm{B}_{1 \mathrm{x}} / \mathrm{C}_{1 \mathrm{x}} / \mathrm{A}_{2 \mathrm{y}}$, and firm $1 \mathrm{Y}$ provides components $A_{1 y} / B_{1 y} / C_{1 y} / A_{2 x}$.

The firms' profit functions $\Pi_{1 \mathrm{x}}, \Pi_{1 \mathrm{y}}$ are given as follows:

$$
\begin{aligned}
& \Pi_{1 \mathrm{x}}=\mathrm{P}_{1 \mathrm{x}} \mathrm{D}_{\mathrm{A} 1 \mathrm{x}}+\mathrm{Q}_{1 \mathrm{x}} \mathrm{D}_{\mathrm{B} 1 \mathrm{x}}+\mathrm{R}_{1 \mathrm{x}} \mathrm{D}_{\mathrm{C} 1 \mathrm{x}}+\mathrm{P}_{2 \mathrm{y}} \mathrm{D}_{\mathrm{A} 2 \mathrm{y}} \\
& \Pi_{1 \mathrm{y}}=\mathrm{P}_{1 \mathrm{y}} \mathrm{D}_{\mathrm{A} 1 \mathrm{y}}+\mathrm{Q}_{1 \mathrm{y}} \mathrm{D}_{\mathrm{B} 1 \mathrm{y}}+\mathrm{R}_{1 \mathrm{y}} \mathrm{D}_{\mathrm{C} 1 \mathrm{y}}+\mathrm{P}_{2 \mathrm{x}} \mathrm{D}_{\mathrm{A} 2 \mathrm{x}} .
\end{aligned}
$$

The first-order conditions of profit maximization can be obtained by differentiating profit functions $\Pi_{1 \mathrm{x}}, \Pi_{1 \mathrm{y}}$ from prices $\mathrm{P}_{1 \mathrm{x}} / \mathrm{Q}_{1 \mathrm{x}} / \mathrm{R}_{1 \mathrm{x}} / \mathrm{P}_{2 \mathrm{y}}, \mathrm{P}_{1 \mathrm{y}} / \mathrm{Q}_{1 \mathrm{y}} / \mathrm{R}_{1 \mathrm{y}} / \mathrm{P}_{2 \mathrm{x}}$. The equilibrium prices and quantities are shown in Table 4.

$<$ Table 4>

\subsubsection{The simultaneous model of one/two-way connections with single entry}

The simultaneous model of one/two-way connections is now developed so that only firm 1X merges with firm 2Y. The simultaneous model of one/two-way connections with single entry (abbreviated as $1 / 2 \mathrm{w}+\mathrm{s}$ ) means that firm $1 \mathrm{X}$ provides components $A_{1 x} / B_{1 x} / C_{1 x} / A_{2 y}$, firm $2 X$ provides $A_{2 x}$, and firm $1 Y$ provides components 
$A_{1 y} / B_{1 y} / C_{1 y}$

The firms' profit functions $\Pi_{1 \mathrm{x}}, \Pi_{2 \mathrm{x}}, \Pi_{1 \mathrm{y}}$ are given as follows:

$$
\begin{aligned}
& \Pi_{1 x}=P_{1 x} D_{A 1 x}+Q_{1 x} D_{B 1 x}+R_{1 x} D_{C 1 x}+P_{2 y} D_{A 2 y} \\
& \Pi_{2 x}=P_{2 x} D_{A 2 x} \\
& \Pi_{1 y}=P_{1 y} D_{A 1 y}+Q_{1 y} D_{B 1 y}+R_{1 y} D_{C 1 y^{*}}
\end{aligned}
$$

The first-order conditions of profit maximization can be obtained by differentiating profit functions $\Pi_{1 x}, \Pi_{2 x}, \Pi_{1 y}$ from prices $P_{1 x} / Q_{1 x} / R_{1 x} / P_{2 y}, P_{2 x}, P_{1 y} / Q_{1 y} / R_{1 y}$. The equilibrium prices and quantities are shown in Table 5.

$<$ Table 5>

3.2.4. The result of the analysis of the simultaneous models of one/two-way connections

Now let us investigate the result of the simultaneous models of one/two-way connections. The main conclusions obtained from Tables 3 to 5 can be summarized as the following lemmas and propositions.

Lemma 2.1 (The comparison of components' prices between $1 / 2 \mathrm{w}$ and $1 / 2 \mathrm{w}+\mathrm{c}$ ): 


$$
\begin{aligned}
& P_{1 x}{ }^{1 / 2 w}=P_{1 y}^{1 / 2 w}>P_{1 x}{ }^{1 / 2 w+c}=P_{1 y}^{1 / 2 w+c}, P_{2 x}^{1 / 2 w}=P_{2 y}^{1 / 2 w}>P_{2 x}{ }^{1 / 2 w+c}=P_{2 y}^{1 / 2 w+c} \\
& Q_{1 x}{ }^{1 / 2 w}=Q_{1 y}^{1 / 2 w}<Q_{1 x}^{1 / 2 w+c}=Q_{1 y}{ }^{1 / 2 w+c}, R_{1 x}{ }^{1 / 2 w}=R_{1 y}{ }^{1 / 2 w}>R_{1 x}{ }^{1 / 2 w+c}=R_{1 y}{ }^{1 / 2 w+c}
\end{aligned}
$$

Lemma 2.2 (The comparison of components' prices between $1 / 2 w$ and $1 / 2 w+s$ ):

$$
\begin{aligned}
& \mathrm{P}_{1 \mathrm{x}}{ }^{1 / 2 \mathrm{w}}<\mathrm{P}_{1 \mathrm{x}}{ }^{1 / 2 \mathrm{w}+\mathrm{s}}, \mathrm{P}_{2 \mathrm{x}}{ }^{1 / 2 \mathrm{w}}<\mathrm{P}_{2 \mathrm{x}}{ }^{1 / 2 \mathrm{w}+\mathrm{s}}, \mathrm{Q}_{1 \mathrm{x}}{ }^{1 / 2 \mathrm{w}}<\mathrm{Q}_{1 \mathrm{x}}{ }^{1 / 2 \mathrm{w}+\mathrm{s}}, \mathrm{R}_{1 \mathrm{x}}{ }^{1 / 2 \mathrm{w}}>\mathrm{R}_{1 \mathrm{x}}{ }^{1 / 2 \mathrm{w}+\mathrm{s}} \\
& \mathrm{P}_{1 \mathrm{y}}{ }^{1 / 2 \mathrm{w}}>\mathrm{P}_{1 \mathrm{y}}{ }^{1 / 2 \mathrm{w}+\mathrm{s}}, \mathrm{P}_{2 \mathrm{y}}{ }^{1 / 2 \mathrm{w}}>\mathrm{P}_{2 \mathrm{y}}{ }^{1 / 2 w+s}, \mathrm{Q}_{1 \mathrm{y}}{ }^{1 / 2 \mathrm{w}}<\mathrm{Q}_{1 \mathrm{y}}{ }^{1 / 2 \mathrm{w}+\mathrm{s}}, \mathrm{R}_{1 \mathrm{y}}{ }^{1 / 2 \mathrm{w}}>\mathrm{R}_{1 \mathrm{y}}{ }^{1 / 2 \mathrm{w}+\mathrm{s}}
\end{aligned}
$$

Lemma 2.3 (The comparison of components' prices between $1 / 2 w+c$ and $1 / 2 w+s$ ):

$$
\begin{aligned}
& \mathrm{P}_{1 \mathrm{x}}{ }^{1 / 2 w+c}<\mathrm{P}_{1 \mathrm{x}}{ }^{1 / 2 w+s}, \mathrm{P}_{2 \mathrm{x}}{ }^{1 / 2 w+c}<\mathrm{P}_{2 \mathrm{x}}^{1 / 2 \mathrm{w}+\mathrm{s}}, \mathrm{Q}_{1 \mathrm{x}}{ }^{1 / 2 \mathrm{w}+\mathrm{c}}>\mathrm{Q}_{1 \mathrm{x}}{ }^{1 / 2 \mathrm{w}+\mathrm{s}}, \mathrm{R}_{1 \mathrm{x}}{ }^{1 / 2 w+c}<\mathrm{R}_{1 \mathrm{x}}{ }^{1 / 2 \mathrm{w}+\mathrm{s}} \\
& \mathrm{P}_{1 \mathrm{y}}{ }^{1 / 2 w+c}>\mathrm{P}_{1 \mathrm{y}}{ }^{1 / 2 w+s}, \mathrm{P}_{2 \mathrm{y}}{ }^{1 / 2 w+c}>\mathrm{P}_{2 \mathrm{y}}{ }^{1 / 2 w+s}, \mathrm{Q}_{1 \mathrm{y}}{ }^{1 / 2 w+c}>\mathrm{Q}_{1 \mathrm{y}}{ }^{1 / 2 w+s}, \mathrm{R}_{1 \mathrm{y}}{ }^{1 / 2 w+c}<\mathrm{R}_{1 \mathrm{y}}{ }^{1 / 2 w+s} .
\end{aligned}
$$

Lemma 2.1 compares the components' prices between the simultaneous model $(1 / 2 w)$ and one with cross entry $(1 / 2 w+c)$. Lemma 2.2 compares the components' prices between the simultaneous model $(1 / 2 w)$ and one with single entry $(1 / 2 w+s)$. Lemma 2.3 compares the components' prices between the simultaneous model with cross entry $(1 / 2 w+c)$ and one with single entry $(1 / 2 w+s)$. The calculation results are quite complicated, and therefore it would be tedious to comment on each result. The most interesting issue is how the prices of $A_{2 x}$ and $A_{2 y}$ would change after the mergers of entrants by dominant firms operating in other areas, which is presented in Lemma 2.1. It may be intuitively expected that the prices of merged components $A_{2 x}$ and $A_{2 y}$ are likely to increase because the number of firms decreases. However, the result is the opposite. As the consequence of cross entry of dominant firms, the prices of merged components $A_{2 x}$ and $A_{2 y}$ decrease. This is because a kind of two-way competition begins to work between areas with the cross entry. 
Proposition 2.1 (The comparison of total outputs between $1 / 2 \mathrm{w}$ and $1 / 2 \mathrm{w}+\mathrm{c}$ ):

$$
\Sigma \Sigma \Sigma \mathrm{D}^{1 / 2 \mathrm{w}}<\Sigma \Sigma \Sigma \mathrm{D}^{1 / 2 w+c}
$$

Proposition 2.2 (The comparison of total outputs between $1 / 2 w$ and $1 / 2 w+s$ ):

$$
\Sigma \Sigma \Sigma D^{1 / 2 w}<\Sigma \Sigma \Sigma D^{1 / 2 w+s}
$$

Proposition 2.3 (The comparison of total outputs between $1 / 2 w+c$ and $1 / 2 w+s$ ):

$$
\Sigma \Sigma \Sigma \mathrm{D}^{1 / 2 w+c}>\Sigma \Sigma \Sigma \mathrm{D}^{1 / 2 w+8}
$$

Proposition 2.1 compares the total outputs between the simultaneous model $(1 / 2 w)$ and one with cross entry $(1 / 2 w+c)$. Proposition 2.2 compares the total outputs between the simultaneous model $(1 / 2 w)$ and one with single entry $(1 / 2 w+s)$. Proposition 2.3 compares the total outputs between the simultaneous model with cross entry $(1 / 2 w+c)$ and one with single entry $(1 / 2 w+s)$. The calculation results are in line with exactly what one would intuitively expect from Lemmas given above. Proposition 2.1 states that cross entry is more socially desirable than no entry in that the total output of the cross entry model is larger than that of the no entry model. Proposition 2.2 states that single entry is more socially desirable than no entry in that the total output of the single entry model is larger than that of the no entry model. Proposition 2.3 states that cross entry is more socially desirable than single entry in that the total output of the cross entry model is larger than that of the single entry model. It follows from the above propositions that the larger the number of entrants, the more socially desirable. 


\subsection{The analysis of the sequential models of one/two-way connections}

In this section, two kinds of sequential models of one-way and two-way connections, namely the one-way-1st/two-way-2nd model and the two-way-1st/oneway-2nd model, will be investigated.

\subsubsection{The one-way-1st/ two-way-2nd model}

We will consider the sequential model where one-way connection is determined in the first term and two-way connection is determined in the second term (abbreviated as $1->2 w$ ). In the first term, one-way connection is solved: firms $1 \mathrm{X}$ and $1 \mathrm{Y}$ determine $A_{1 \mathrm{x}} / \mathrm{B}_{1 \mathrm{x}}$ and $\mathrm{A}_{1 \mathrm{y}} / \mathrm{B}_{1 \mathrm{y}}$ respectively; furthermore, firms $2 \mathrm{X}$ and $2 \mathrm{Y}$ determine $A_{2 x}$ and $A_{2 y}$ respectively. In the second term, two-way connection is solved: firms $1 X$ and $1 \mathrm{Y}$ determine $\mathrm{C}_{1 \mathrm{x}}$ and $\mathrm{C}_{1 \mathrm{y}}$ respectively.

The ownership structure of components and the profit functions can be represented in the same way as the simultaneous model. The first-order conditions of profit maximization can be obtained by differentiating profit functions $\Pi_{1 \mathrm{x}}, \Pi_{2 \mathrm{x}}, \Pi_{1 \mathrm{y}}, \Pi_{2 \mathrm{y}}$ from prices $P_{1 x} / Q_{1 x}, P_{2 x}, P_{1 y} / Q_{1 y}, P_{2 y}$ in the first term, then from prices $R_{1 x}, R_{1 y}$ in the second term. The model can be solved by the normal backward-induction. The equilibrium prices and quantities are displayed in Table 6. 
$<$ Table 6>

\subsubsection{The two-way-1st/ one-way-2nd model}

We will consider the sequential model where two-way connection is determined in the first term and one-way connection is determined in the second term (abbreviated as $2->1 w$ ). In the first term, two-way connection is solved: firms $1 \mathrm{X}$ and $1 \mathrm{Y}$ determine $\mathrm{C}_{1 \mathrm{x}}$ and $\mathrm{C}_{1 \mathrm{y}}$ respectively. In the second term, one-way connection is solved: firms $1 X$ and $1 Y$ determine $A_{1 x} / B_{1 x}$ and $A_{1 y} / B_{1 y}$ respectively; furthermore, firms $2 \mathrm{X}$ and $2 \mathrm{Y}$ determine $\mathrm{A}_{2 \mathrm{x}}$ and $\mathrm{A}_{2 \mathrm{y}}$ respectively.

The ownership structure of components and the profit functions can be represented in the same way as the simultaneous model. The first-order conditions of profit maximization can be obtained by differentiating profit functions $\Pi_{1 \mathrm{x}}, \Pi_{2 \mathrm{x}}, \Pi_{1 \mathrm{y}}, \Pi_{2 \mathrm{y}}$ from prices $R_{1 x}, R_{1 y}$ in the first term, then from prices $P_{1 x} / Q_{1 x}, P_{2 x}, P_{1 y} / Q_{1 y}, P_{2 y}$ in the second term. The model can be solved by the normal backward-induction. The equilibrium prices and quantities are shown in Table 7.

$<$ Table 7>

3.3.3. The result of the analysis of the sequential models of one/two-way 
connections

Now let us investigate the result of the sequential models of one/two-way connections. The main conclusions obtained from Tables 3,6 and 7 can be summarized as the following lemmas and propositions.

Lemma 3.1 (The comparison of components' prices between $1 / 2 w$ and $1->2 w$ ):

$$
\begin{aligned}
& P_{1 x}^{1 / 2 w}=P_{1 y}^{1 / 2 w}<P_{1 x}^{1 \rightarrow 2 w}=P_{1 y}^{1-2 w}, P_{2 x}^{1 / 2 w}=P_{2 y}^{1 / 2 w}<P_{2 x}^{1 \rightarrow 2 w}=P_{2 y}^{1 \rightarrow 2 w}, \\
& Q_{1 x}^{1 / 2 w}=Q_{1 y}^{1 / 2 w}<Q_{1 x}^{1 \rightarrow 2 w}=Q_{1 y}^{1-2 w}, R_{1 x}^{1 / 2 w}=R_{1 y}^{1 / 2 w}>R_{1 x}^{1 \rightarrow 2 w}=R_{1 y}^{1 \rightarrow>2 w} .
\end{aligned}
$$

Lemma 3.2 (The comparison of components' prices between $1 / 2 \mathrm{w}$ and $2->1 \mathrm{w}$ ):

$$
\begin{aligned}
& \mathrm{P}_{1 \mathrm{x}}^{1 / 2 \mathrm{w}}=\mathrm{P}_{1 \mathrm{y}}{ }^{1 / 2 \mathrm{w}}>\mathrm{P}_{1 \mathrm{x}}{ }^{2-\rightarrow 1 \mathrm{w}}=\mathrm{P}_{1 \mathrm{y}}{ }^{2 \rightarrow 1 \mathrm{w}}, \mathrm{P}_{2 \mathrm{x}}{ }^{1 / 2 \mathrm{w}}=\mathrm{P}_{2 \mathrm{y}}{ }^{1 / 2 \mathrm{w}}>\mathrm{P}_{2 \mathrm{x}}{ }^{2 \rightarrow 1 \mathrm{w}}=\mathrm{P}_{2 \mathrm{y}}{ }^{2 \rightarrow 1 \mathrm{w}}, \\
& \mathrm{Q}_{1 \mathrm{x}}{ }^{1 / 2 \mathrm{w}}=\mathrm{Q}_{1 \mathrm{y}}{ }^{1 / 2 \mathrm{w}}>\mathrm{Q}_{1 \mathrm{x}}{ }^{2 \rightarrow 1 \mathrm{w}}=\mathrm{Q}_{1 \mathrm{y}}{ }^{2 \rightarrow 1 \mathrm{w}}, \mathrm{R}_{1 \mathrm{x}}{ }^{1 / 2 \mathrm{w}}=\mathrm{R}_{1 \mathrm{y}}{ }^{1 / 2 \mathrm{w}}<\mathrm{R}_{1 \mathrm{x}}{ }^{2 \rightarrow \mathrm{Iw}}=\mathrm{R}_{1 \mathrm{y}}{ }^{2 \rightarrow 1 \mathrm{w}}
\end{aligned}
$$

Lemma 3.3 (The comparison of components' prices between $1->2 w$ and $2->1 w$ ):

$$
\begin{aligned}
& P_{1 x}^{1->2 w}=P_{1 y}^{1->2 w}>P_{1 x}^{2->1 w}=P_{1 y}^{2->1 w}, P_{2 x}^{1->2 w}=P_{2 y}^{1->2 w}>P_{2 x}^{2->1 w}=P_{2 y}^{2 \rightarrow 1 w}, \\
& \mathrm{Q}_{1 \mathrm{x}}{ }^{1 \rightarrow 2 \mathrm{w}}=\mathrm{Q}_{1 \mathrm{y}}{ }^{1 \rightarrow \rightarrow 2 \mathrm{w}}>\mathrm{Q}_{1 \mathrm{x}}{ }^{2 \rightarrow 1 \mathrm{w}}=\mathrm{Q}_{1 \mathrm{y}}{ }^{2 \rightarrow 1 \mathrm{w}}, \mathrm{R}_{1 \mathrm{x}}{ }^{1 \rightarrow>2 \mathrm{w}}=\mathrm{R}_{1 \mathrm{y}}{ }^{1->2 \mathrm{w}}<\mathrm{R}_{1 \mathrm{x}}{ }^{2-\rightarrow 1 \mathrm{w}}=\mathrm{R}_{1 \mathrm{y}}{ }^{2 \rightarrow 1 \mathrm{w}} \text {. }
\end{aligned}
$$

Proposition 3.1 (The comparison of total outputs between $1 / 2 \mathrm{w}$ and $1->2 w$ ):

$$
\Sigma \Sigma \Sigma \mathrm{D}^{1 / 2 w}>\Sigma \Sigma \Sigma \mathrm{D}^{1->2 w}
$$

Proposition 3.2 (The comparison of total outputs between $1 / 2 \mathrm{w}$ and $2 \rightarrow 1 \mathrm{w}$ ):

$$
\Sigma \Sigma \Sigma \mathrm{D}^{1 / 2 w}>\Sigma \Sigma \Sigma \mathrm{D}^{2->1 w}
$$

Proposition 3.3 (The comparison of total outputs between $1->2$ w and $2->1 w$ ):

$$
\Sigma \Sigma \Sigma \mathrm{D}^{1->2 \mathrm{w}}<\Sigma \Sigma \Sigma \mathrm{D}^{2 \rightarrow 1 \mathrm{w}}
$$


Lemma 3.1. compares the components' prices between the simultaneous model $(1 / 2 w)$ and the one-way-1st/two-way-2nd model $(1->2 w)$. Proposition 3.1 compares the total outputs between them. Similarly, Lemma 3.2 compares the components' prices between the simultaneous model $(1 / 2 \mathrm{w})$ and the two-way-1st/oneway-2nd model $(2->1 w)$. Proposition 3.2 compares the total outputs between them. In the one-way-1st/two-way-2nd model, the prices of one-way connection determined in the first term increase while the prices of two-way connection determined in the second term decrease, on the basis of the simultaneous model. On the other hand, in the twoway-1st/one-way-2nd model, the prices of two-way connection determined in the first term increase while the prices of one-way connection determined in the second term decrease, on the basis of the simultaneous model. Thus, in these sequential models, the prices determined first are considered to increase while the prices determined second are considered to decrease, compared with the simultaneous model. Furthermore, the simultaneous model is more socially desirable than the sequential models in that the total output of the simultaneous model is larger than those of the sequential models.

Lemma 3.3 compares the components' prices between the one-way-1st/twoway-2nd model $(1->2 w)$ and the two-way-1st/one-way-2nd model (2->1w). Proposition 3.3 compares the total outputs between them. It is also observed here that the prices determined first increase while the prices determined second decrease. Furthermore, the two-way-1st/one-way-2nd model is more socially desirable than the 
one-way-1st/two-way-2nd model in that the total output of the two-way-1st/one-way2nd model is larger than that of the one-way-1st/two-way-2nd model. It follows from what has been observed that the local bottleneck of one-way connection should be determined afterward rather than beforehand, or in other words the backbone interconnection of two-way connection should be decided beforehand rather than afterward.

\section{Conclusion}

This paper has firstly analyzed one-way and two-way connections with the two-level components model and secondly attempted to integrate them with the threelevel components model. Although the original purpose of this paper was to study the network of networks such as the Internet, the analysis framework itself can easily be applied to any other vertically industrial structure. Three main conclusions have been obtained in this paper: first, two-way connection is more socially desirable than oneway connection; second, cross entry is more socially desirable than no entry, and also cross entry is more socially desirable than single entry; third, the local structure of oneway connection and the global structure of two-way connection should be determined at the same time, and, if any, the local bottleneck of one-way connection should be determined afterward rather than beforehand, or in other words the global interconnection of two-way connection should be decided beforehand rather than afterward. 
Finally we have to refer briefly to two subjects worthy of future research. The first is to develop the generality of the analytical assumptions and the second is to extend the analytical scope. We have assumed the linear demand functions, following the previous research, but will have to assume more general demand functions to confirm the robustness of our conclusions. We have also considered total outputs as an index indicating social welfare. However, more precisely, we should calculate the social welfare as the sum of consumer surplus and producer surplus. In addition, we should take account of other social values like the ineentive effects in management and the stable supply of services. Next, we have established the model basically keeping the Japanese Internet structure in mind but will have to consider the other models depending on industrial structures peculiar to other countries. We consider these to be subjects for future research. 


\section{References}

Armstrong, M., C. Doyle and J. Vickers, 1996; The Access Pricing Problem: A Synthesis, The Journal of Industrial Economics 44.2, 131-150.

Armstrong, M., 1998, Interconnection in Telecommunications, Economic Journal 108, 545-564.

Baumol, J. B. and J. G. Sidak, 1994, Toward Competition in Local Telephony (MIT Press).

Economides; N., 1989, Desirability of Compatibility in the Absence of Network Externalities, American Economic Review 79, 1165-1181.

Economides, N. and S.C. Salop, 1992, Competition and Integration among Complements, and Network Market Structure, Journal of Industrial Economics 40.1, 105-23.

Giovannetti, E., 2002, Interconnection, Differentiation and Bottlenecks in the Internet, Information Economics and Policy14.3: 385-404.

Laffont, J. J. and J. Tirole, 1994, Access Pricing and Competition, European Economic Review 38.9, 1673-1710.

Laffont, J. J., P. Ray and J. Tirole, 1998, Network Competition: Overview and Nondiscriminatory Pricing, RAND Journal of Economics 29.1, 1-37.

Laffont, J-J. and J. Tirole, 2000, Competition in Telecommunications (The MIT Press).

Lehr, W., 2001, Vertical Integration, Industry Structure, and Internet Telephony, in: L.W. McKnight, W. Lehr, and D.D. Clark, eds., Internet Telephony (The MIT Press) 
93-124.

MacKie-Mason, J.K. and H.R.Varian, 1997, Economic FAQs about the Internet, in: L.W. McKnight and J.P. Bailey, eds., Internet Economics (The MIT Press) 27-62.

McKnight, L.W. and B. Leida (2001), Internet Telephony Service Providers, in: L.W. McKnight, W. Lehr, and D.D. Clark, eds., Internet Telephony (The MIT Press) $193-215$.

Matutes, C. and P. Regibeau, 1988, Mix and Match: Product Compatibility without Network Externalities, Rand Journal of Economics 19, 221-234.

Matutes, C. and P. Regibeau, 1992, Compatibility and Bundling of Complementary Goods in a Duopoly, Journal of Industrial Economics 40.1, 37-54.

Shy, O., 2001, The Economics of Network Industries (Cambridge University Press). 
Fig. 1. The Internet topology

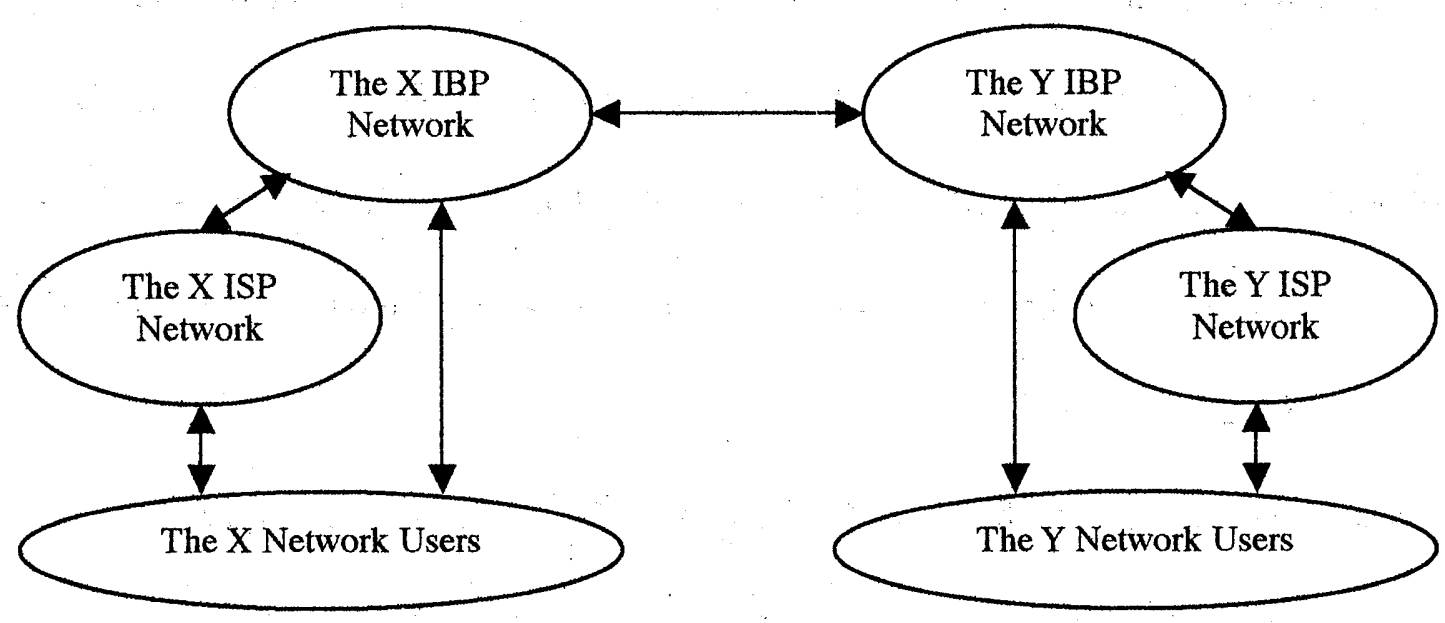

The X Net

The Y Net

Fig. 2. The number of Japanese Internet subscribers according to the types of providers

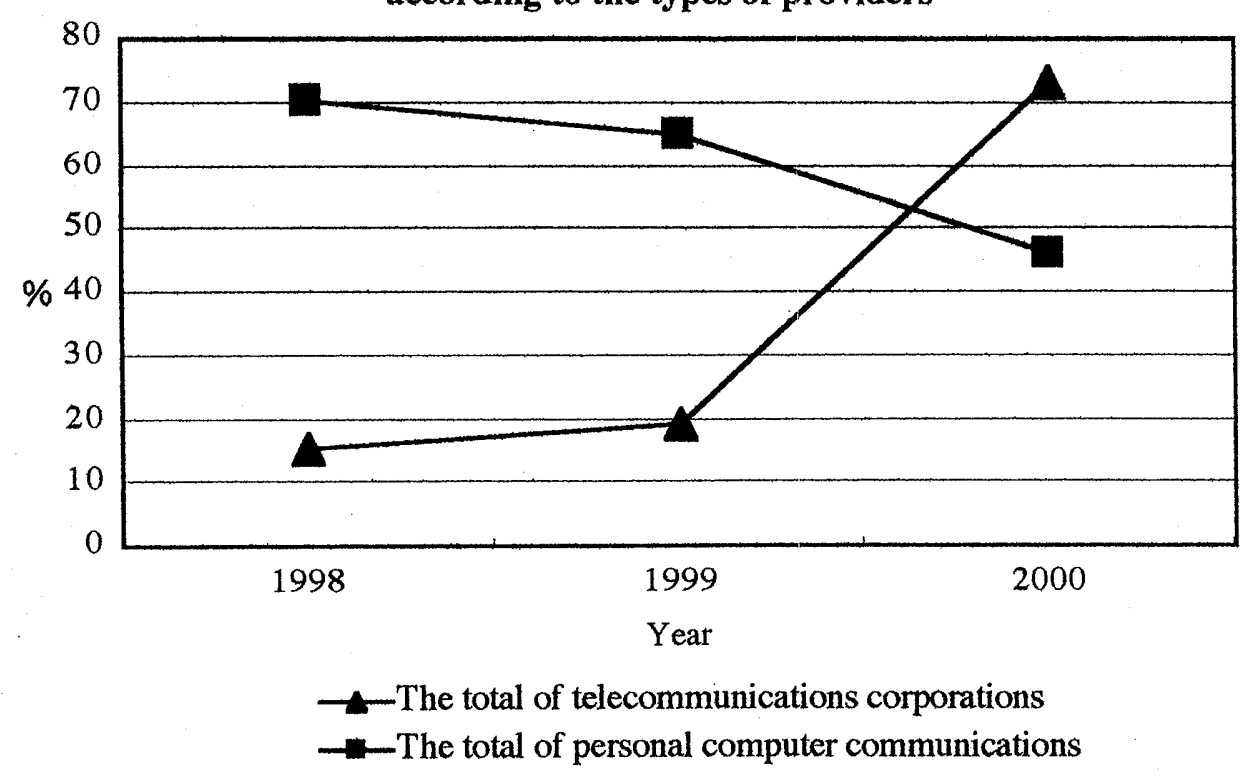


Fig.3. The number of Japanese Internet subscribers to telecommunications corporations

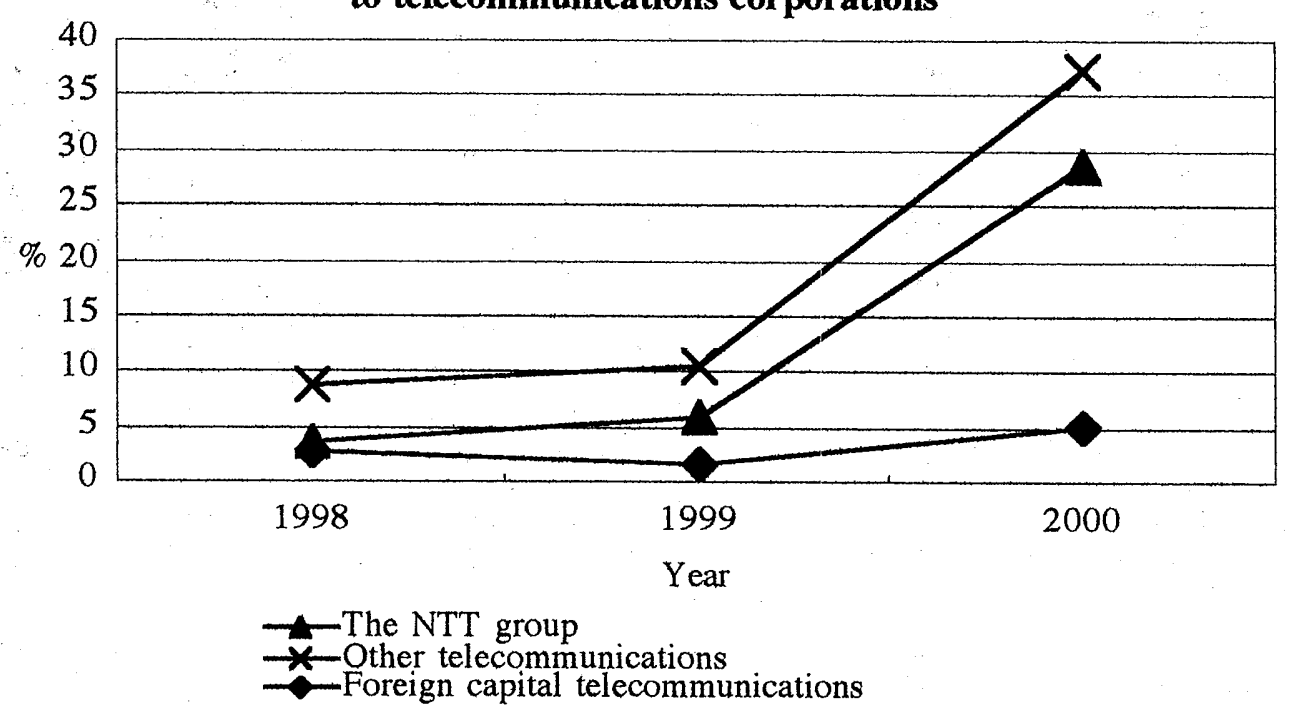

Fig.4. The components models of connection
(a) One-way
(b) Two-way
(c) One/two-way
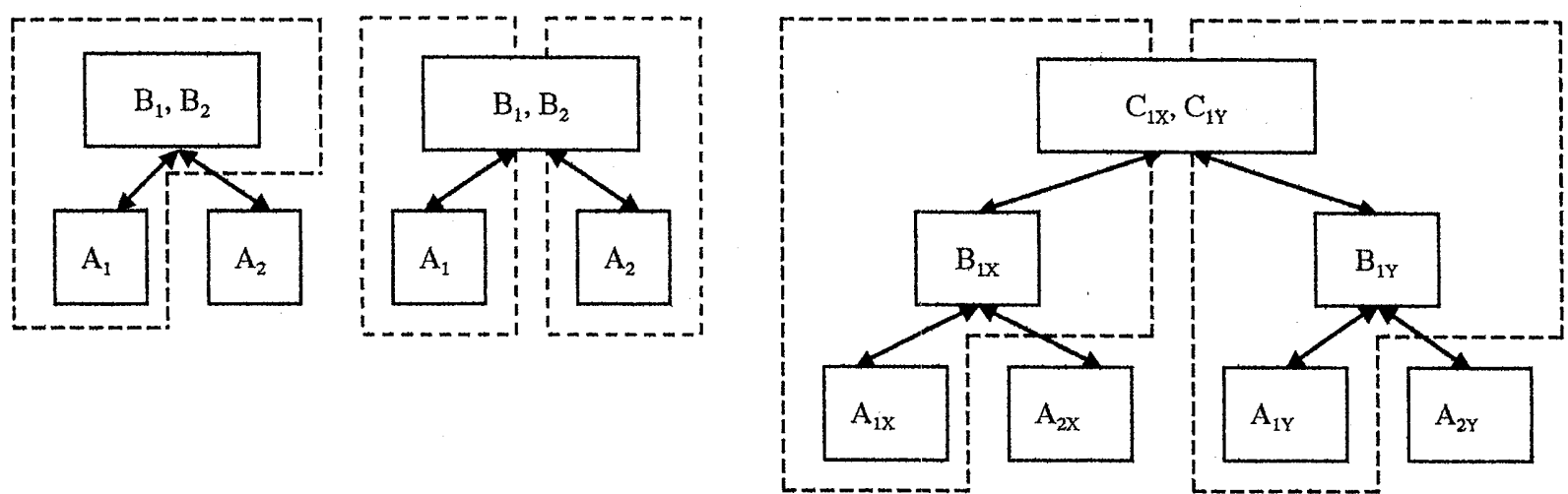


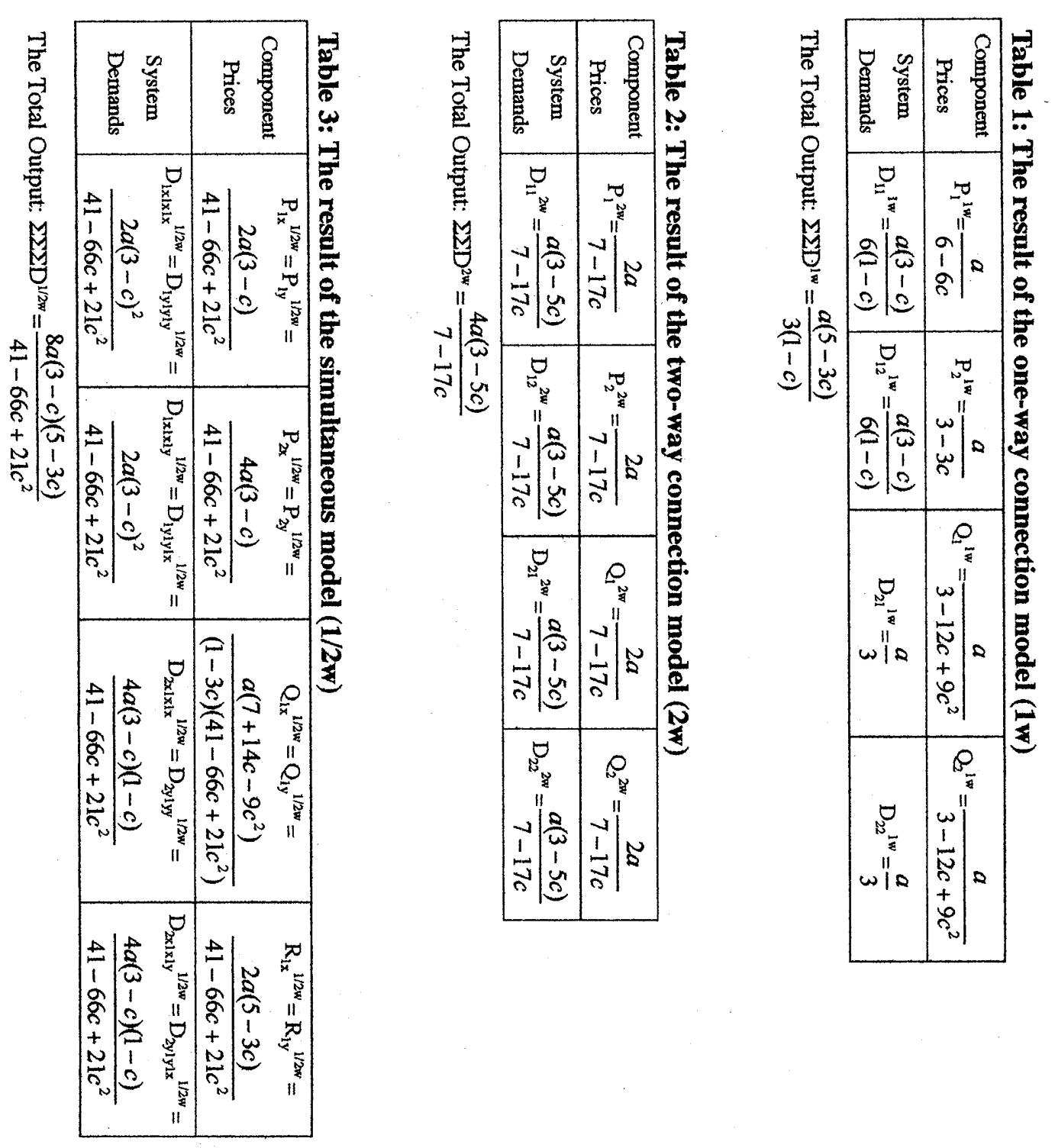



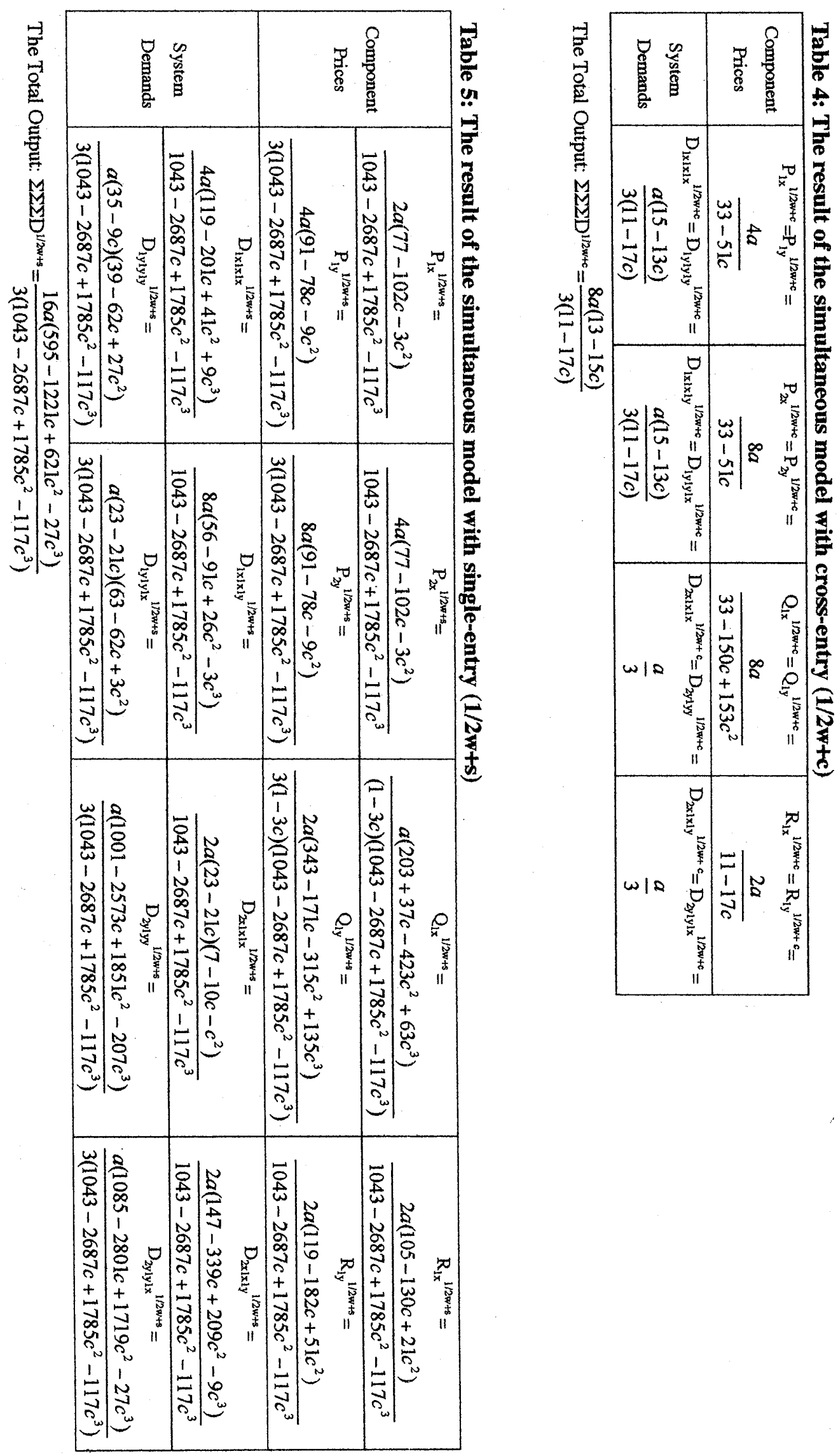

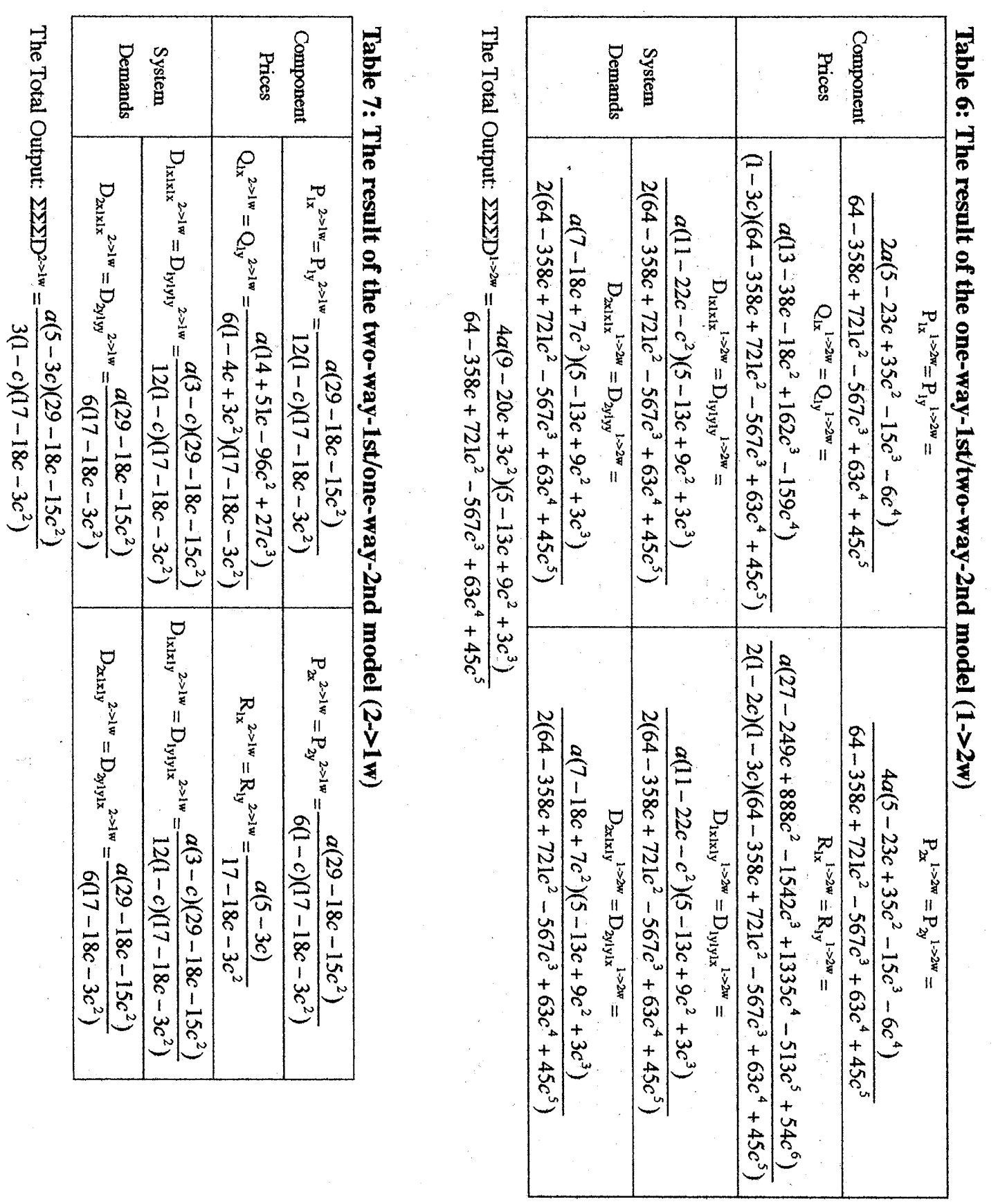


\section{Proof Note}

for "Analysis of Internet Topology with Three-Level Components Model"

All Lemmas and Propositions in this paper can be proved by direct calculations. It would, however, be useful to provide a graphical outline of proof for the intutive understanding (by using Mathematica), although it need not be included in the manuscript.

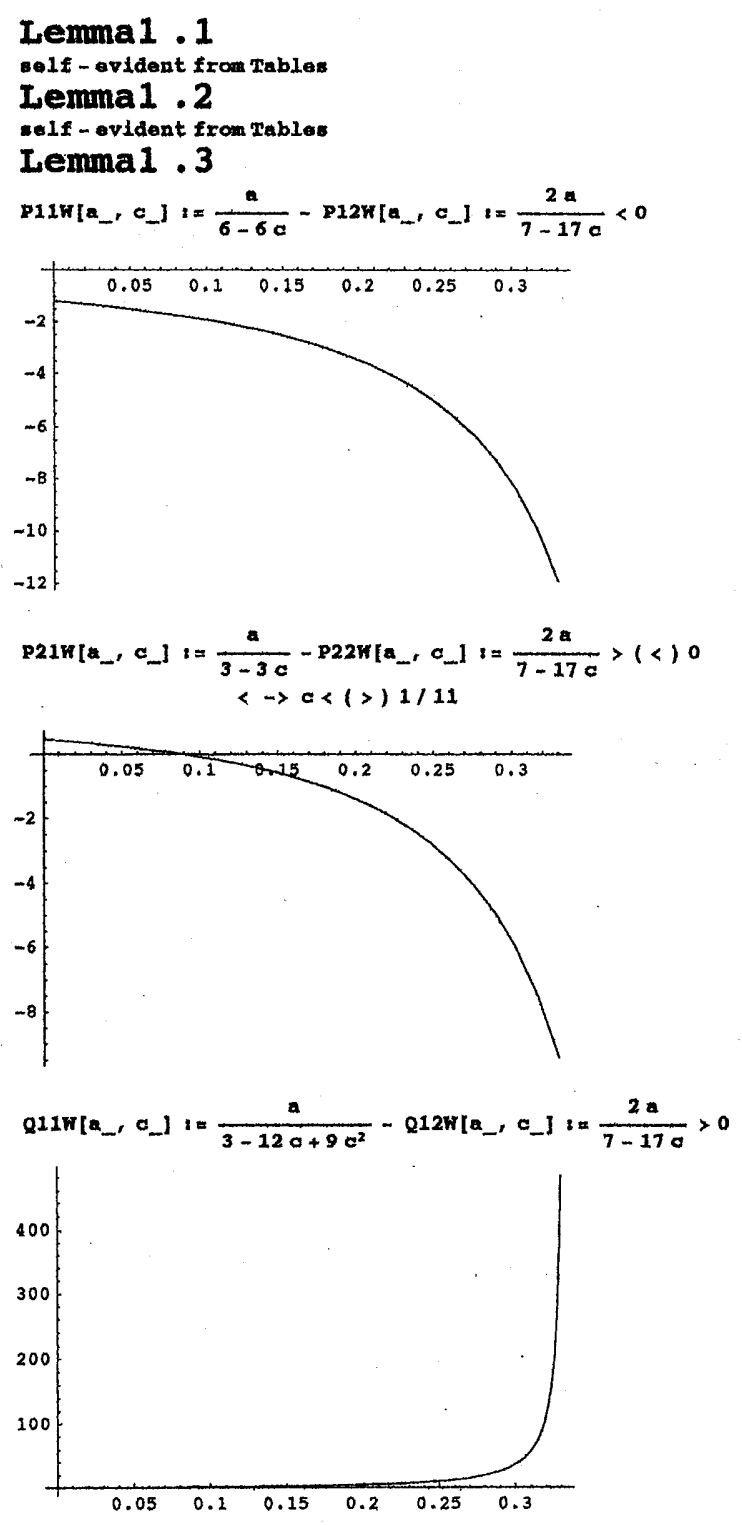




\section{Proposition 1}

TD1K $\left[a_{-}, a_{-}\right]: \frac{a(-5+3 c)}{3(-1+c)}-\operatorname{TD} 2 K\left[a_{-}, c_{-}\right]:=\frac{4 a(-3+5 c)}{-7+17 a}<0$

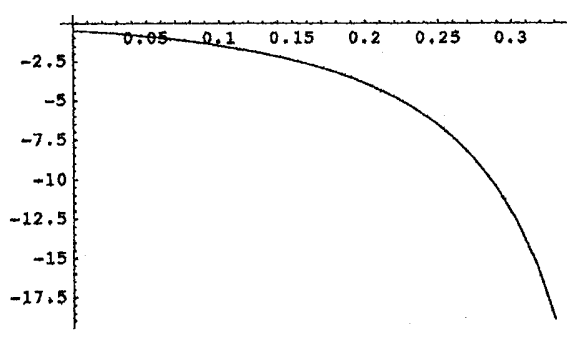

\section{Lemma2 . 1}

$P 1 \times 12 w\left[a_{-}, c_{-}\right]:=\frac{a(6-2 a)}{41-66 a+21 c^{2}}-81 \times 12 W c\left[a_{-}, c_{-}\right] t=\frac{4 a}{33-51 c}>0$

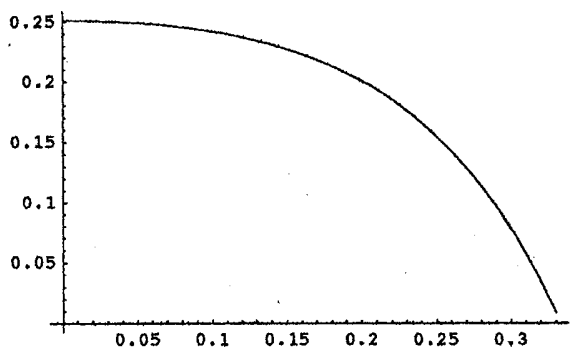

P2X12K[a_, $\left.a_{-}\right]=\frac{a(3-c)}{41-66 a+21 c^{2}}-82 \times 12 H a\left[a_{-}, c_{-}\right]:=\frac{8 a}{33-51 c}>0$

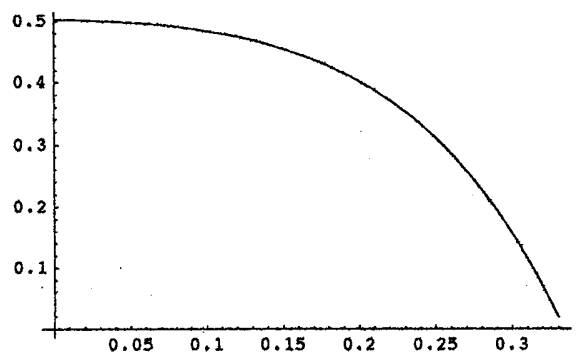

$Q 1 \times 12 W\left[a_{-}, c_{-} 1:=\frac{a\left(7+14 a-9 a^{2}\right)}{(1-3 c)\left(41-66 a+21 c^{2}\right)}-21 \times 12 W c\left[a_{-}, c_{-} 1:=\frac{8 a}{33-150 c+153 a^{2}}<0\right.\right.$

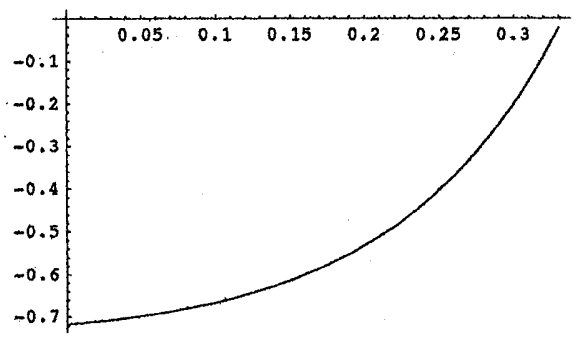

$R 1 \times 12 W\left[a_{-}, a_{-}\right]:=\frac{2 a(5-3 a)}{41-66 a+21 a^{2}}-R 1 \times 12 W c\left[a_{-}, c_{-}\right]:=\frac{2 a}{11-17 c}>0$

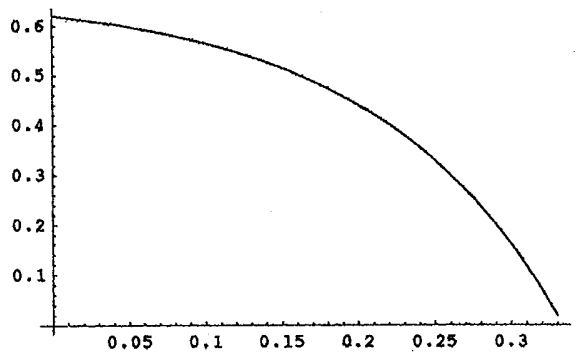




\section{Lemma2 . 2}

$P 1 \times 12 \%[a, c]:=\frac{a(6-2 a)}{41-66 c+21 c^{2}}-P 1 \times 12 H=\left[a_{-}, c_{-}\right]:=\frac{2 a\left(77-102 c-3 c^{2}\right)}{1043-2687 c+1785 c^{2}-117 c^{3}}<0$

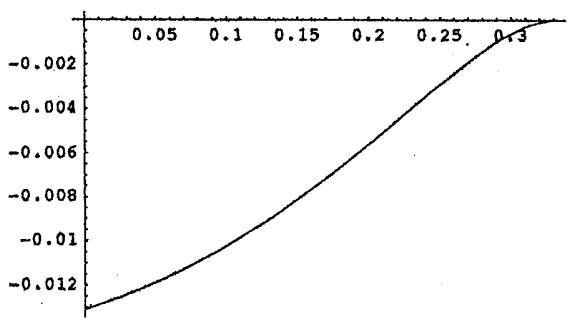

$\operatorname{P2\times 12H}[a, c]:=\frac{4 a(3-c)}{41-66 c+21 c^{2}}-P 2 \times 12$ Ho $\left[a_{-}, c_{-}\right]:=\frac{4 a\left(77-102 a-3 c^{2}\right)}{1043-2687 a+1785 c^{2}-117 c^{3}}<0$

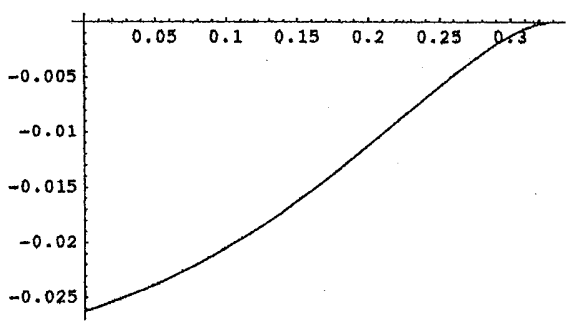

$Q 1 \times 12 ห[a, c]:=\frac{a\left(7+14 c-9 c^{2}\right)}{(1-3 c)\left(41-66 c+21 c^{2}\right)}-01 \times 12 \mathrm{Ha}\left[a, a_{-}\right]:=\frac{a\left(203+37 c-423 c^{2}+63 c^{3}\right)}{(1-3 c)\left(1043-2687 c+1785 c^{2}-117 c^{3}\right)}<0$

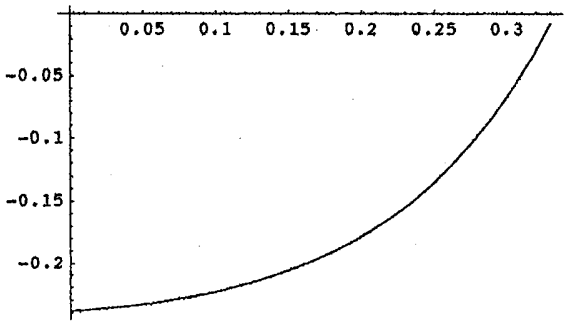

$R 1 \times 12 W[a, c]:=\frac{2 a(5-3 c)}{41-66 c+21 c^{2}}-R 1 \times 12 W s\left[a_{-}, c_{-}\right]:=\frac{2 a\left(105-130 c+21 c^{2}\right)}{1043-2687 c+1785 c^{2}-117 c^{3}}>0$

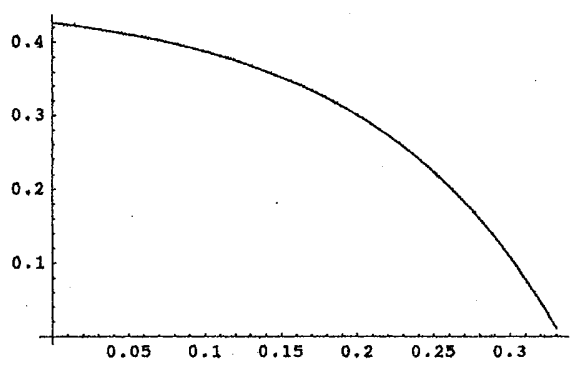

P1Y12K $[a, c]: \quad a(6-2 c) \quad 4 a\left(91-78 a-9 c^{2}\right)$

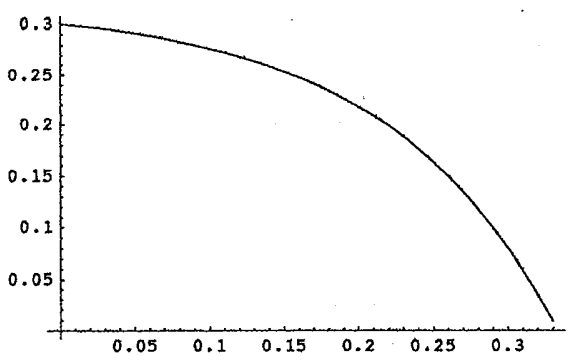


P2Y12W[a, a] $:=\frac{4 a(3-a)}{41-66 c+21 c^{2}}-$ P2Y12Ws $\left[a_{-}, c_{-}\right]:=\frac{8 a\left(91-78 c-9 a^{2}\right)}{3\left(1043-2687 c+1785 a^{2}-117 c^{3}\right)}>0$

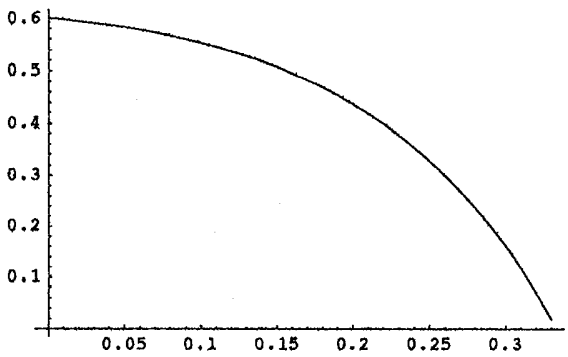

$Q 1 Y^{12 K}[a, c]:=\frac{a\left(7+14 c-9 c^{2}\right)}{(1-3 a)\left(41-66 a+21 c^{2}\right)}-Q^{1} Y_{12} W\left[a_{-}, c_{-}\right]:=\frac{2 a\left(343-171 c-315 c^{2}+135 a^{3}\right)}{3(1-3 a)\left(1043-2687 c+1785 c^{2}-117 c^{3}\right)}<0$

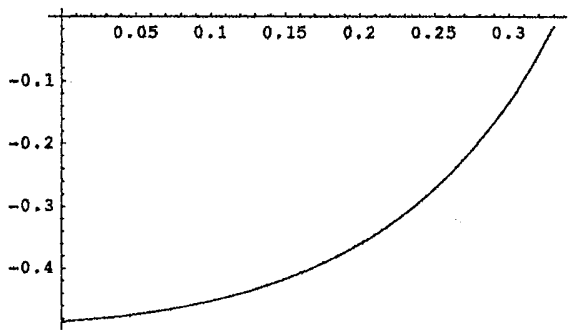

R1Y12W $[a, c]:=\frac{2 a(5-3 c)}{41-66 c+21 a^{2}}-R 1 Y 12 W E\left[a_{-}, c_{-}\right]:=\frac{2 a\left(119-182 c+51 c^{2}\right)}{1043-2687 c+1785 c^{2}-117 c^{3}}>0$

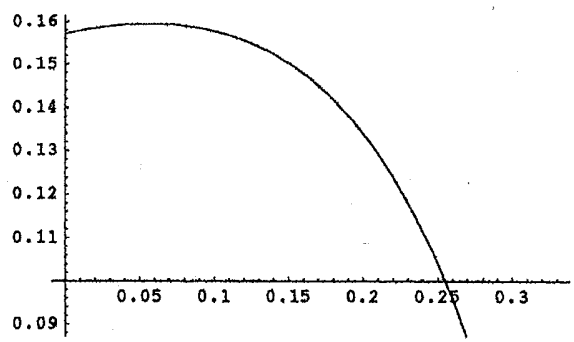

Lemma2 . 3

P1x12Wo[a, $c]:=\frac{a(6-2 a)}{41-66 c+21 a^{2}}-P 1 \times 12 k s[a, d]:=\frac{2 a\left(77-102 c-3 a^{2}\right)}{1043-2687 c+1785 c^{2}-117 c^{3}}<0$

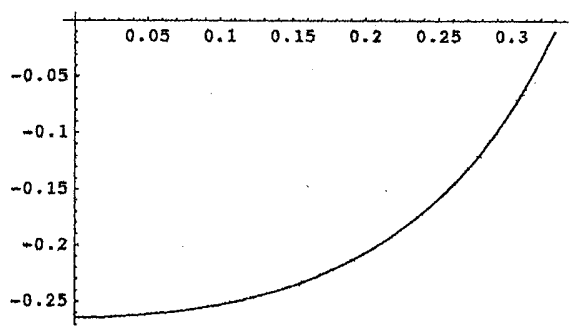

$P 2 \times 12 K c[a, c]:=\frac{4 a(3-c)}{41-66 c+21 c^{2}}-P 2 \times 12 k=[a, c] ;=\frac{4 a\left(77-102 c-3 a^{2}\right)}{1043-2687 a+1785 c^{2}-117 c^{3}}<0$

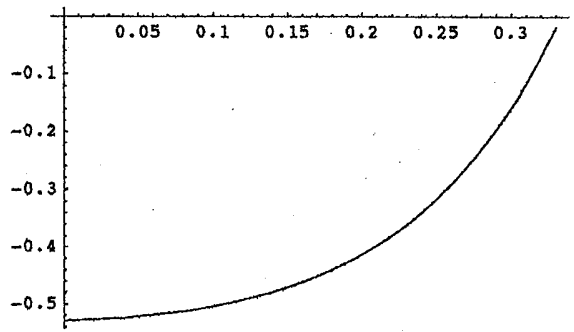


$Q 1 \times 12 W c[a, c]:=\frac{a\left(7+14 c-9 \sigma^{2}\right)}{(1-3 c)\left(41-66 c+21 c^{2}\right)}-Q 1 \times 12 W s[a, c]:=\frac{a\left(203+37 c-423 a^{2}+63 a^{3}\right)}{(1-3 c)\left(1043-2687 c+1785 c^{2}-117 c^{3}\right)}>0$

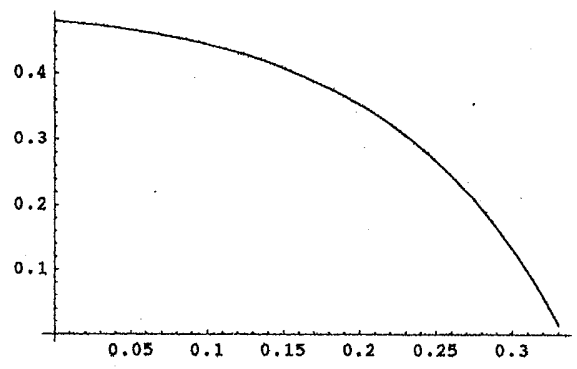

$R 1 \times 12 W \sigma[a, c] t=\frac{2 a(5-3 c)}{41-66 c+21 c^{2}}-R 1 \times 12 \mathrm{H}[a, c]:=\frac{2 a\left(105-130 a+21 a^{2}\right)}{1043-2687 c+1785 c^{2}-117 c^{3}}<0$

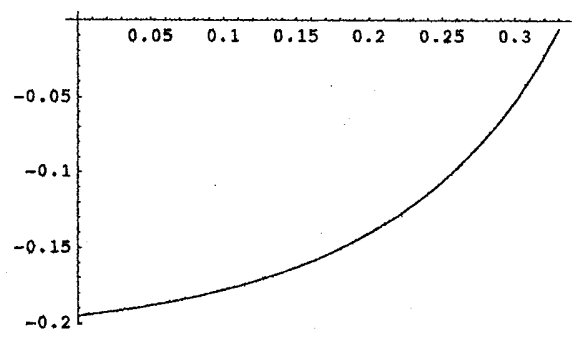

P1Y12Wo[a, o] $:=\frac{a(6-2 c)}{41-66 a+21 c^{2}}-P 1 Y 12 \mathrm{Ws}[\mathrm{a}, \mathrm{c}]:=\frac{4 a\left(91-78 c-9 c^{2}\right)}{3\left(1043-2687 c+1785 c^{2}-117 o^{3}\right)}>0$

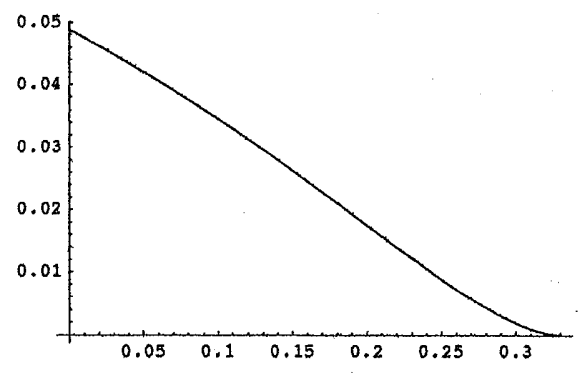

P2Y12Wc[a, c] $:=\frac{4 a(3-a)}{41-66 c+21 c^{2}}-$ P2Y12Ws $[a, c]:=\frac{8 a\left(91-78 c-9 a^{2}\right)}{3\left(1043-2687 c+1785 c^{2}-117 c^{3}\right)}>0$

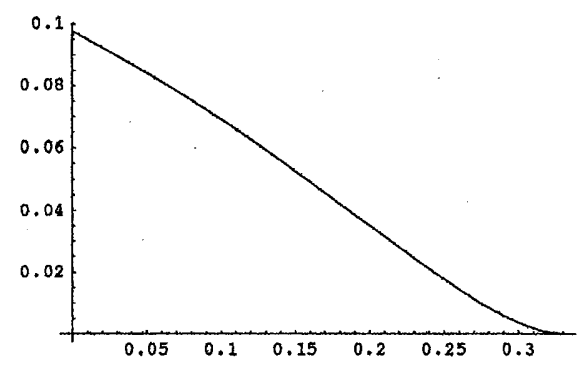

Q1Y12Kc $[a, a]:=\frac{a\left(7+14 c-9 c^{2}\right)}{(1-3 a)\left(41-66 c+21 c^{2}\right)}-Q 1 \mathrm{Y} 12 \mathrm{~W}=[\mathrm{a}, c]:=\frac{2 \mathrm{a}\left(343-171 c-315 c^{2}+135 c^{3}\right)}{3(1-3 c)\left(1043-2687 c+1785 c^{2}-117 c^{3}\right)}>0$

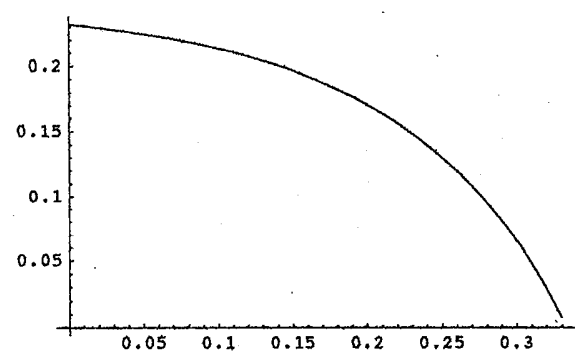


$\operatorname{R1Y} 12 W c[a, c]:=\frac{2 a(5-3 c)}{41-66 a+21 c^{2}}-R 1 Y 12 W[a, a]:=\frac{2 a\left(119-182 c+51 c^{2}\right)}{1043-2687 c+1785 c^{2}-117 c^{3}}<0$

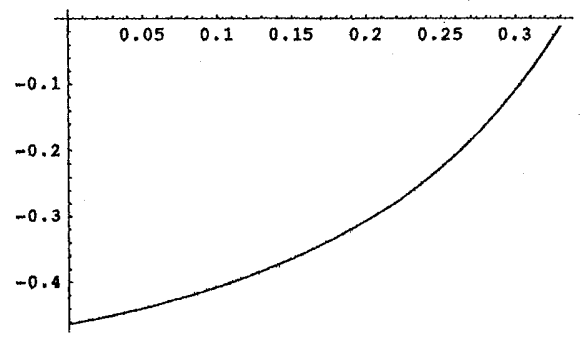

\section{Proposition2 . 1}

$\operatorname{TD} 12 K\left[a_{-}, c_{-}\right]:=\frac{8 a(-3+c)(-5+3 c)}{41-66 c+21 c^{2}}-\operatorname{TD12Kc}\left[a_{-}, a_{-}\right]:=\frac{8 a(-13+15 c)}{3(-11+17 c)}<0$

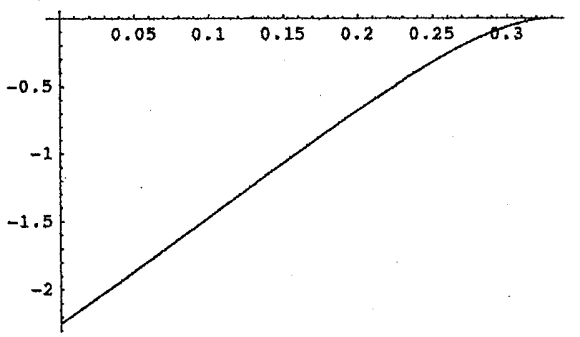

\section{Proposition2 . 2}

TD12W[a, c c $]:=\frac{8 a(-3+c)(-5+3 c)}{1-66 c+21 c^{2}}-\operatorname{TD12Hs}\left[a_{-}, c_{-}\right]:=\frac{16 a\left(-595+1221 a-621 c^{2}+27 c^{3}\right)}{3\left(-1043+2687 c+1785 c^{2}+117 c^{3}\right)}<0$

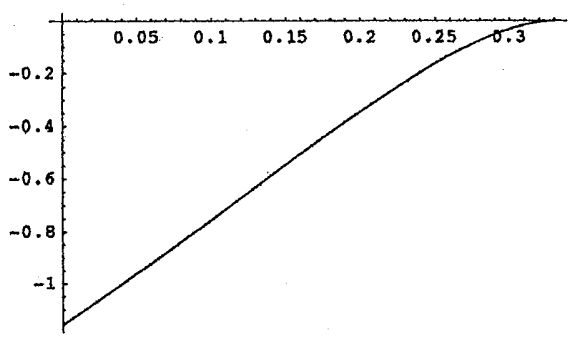

\section{Proposition2 . 3}

TD12Ka $[a, c]:=\frac{8 a(-13+15 a)}{3(-11+17 a)}-\operatorname{TD12WE}[a, a]:=\frac{16 a\left(-595+1221 c-621 c^{2}+27 c^{3}\right)}{3\left(-1043+2687 c-1785 a^{2}+117 c^{3}\right)}>0$

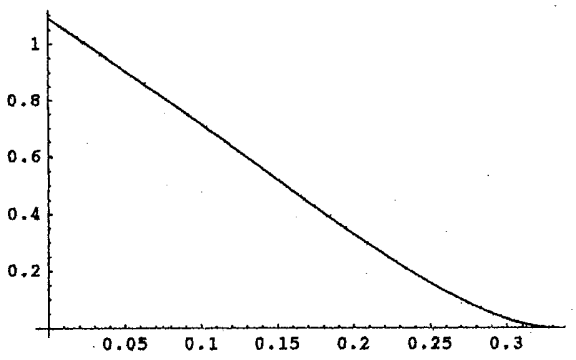

Lemma 3 . 1

p1x1and2 $\left[a_{-}, c_{-}\right]:=\frac{a(6-2 c)}{41-66 c+21 c^{2}}-$ P1x1then2 $\left[a_{-}, c_{-}\right]:=\frac{2 a\left(5-23 c+35 c^{2}-15 c^{3}-6 c^{4}\right)}{64-358 c+721 c^{2}-567 c^{3}+63 c^{4}+45 c^{3}}<0$

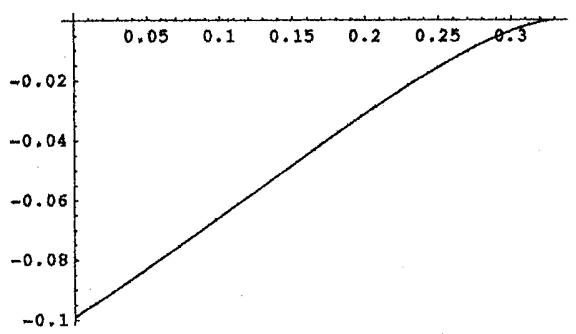


P2x1and2 [a, $\left.c_{-}\right]:=\frac{4 a(3-c)}{41-66 a+21 c^{2}}-$ P2x1then2 $\left[a_{-}, c_{-}\right]:=\frac{4 a\left(5-23 c+35 c^{2}-15 a^{3}-6 a^{4}\right)}{64-358 c+721 c^{2}-567 c^{3}+63 c^{4}+45 o^{5}}<0$

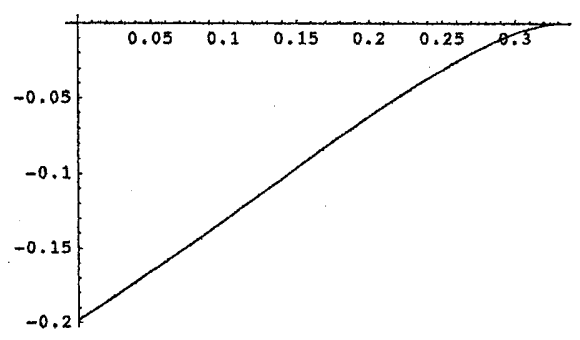

Q1xland2 $\left[a_{-}, c_{-}\right]:=\frac{a\left(7+14 c-9 c^{2}\right)}{(1-3 c)\left(41-66 c+21 a^{2}\right)}-Q 1 \times 1$ then2 $\left[a_{-}, c_{-}\right]:=\frac{a\left(13-38 c-18 c^{2}+162 c^{3}-159 c^{4}\right)}{(1-3 c)\left(64-358 c+721 a^{2}-567 c^{3}+63 c^{4}+45 a^{5}\right)}<0$

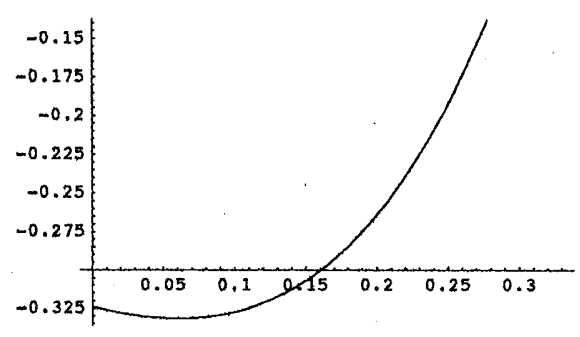

R1x1and2 $\left[a_{-}, a_{-}\right]:=\frac{2 a(5-3 c)}{41-66 c+21 c^{2}}-R 1 \times 1$ then2 $\left[a_{-}, a_{-}\right]:=\frac{a\left(-27+249 c-888 c^{2}+1542 c^{3}-1335 c^{4}+513 c^{5}-54 c^{6}\right)}{2(1-2 c)(-1+3 a)\left(64-3580+721 c^{2}-567 c^{3}+63 a^{4}+45 c^{5}\right)}>0$

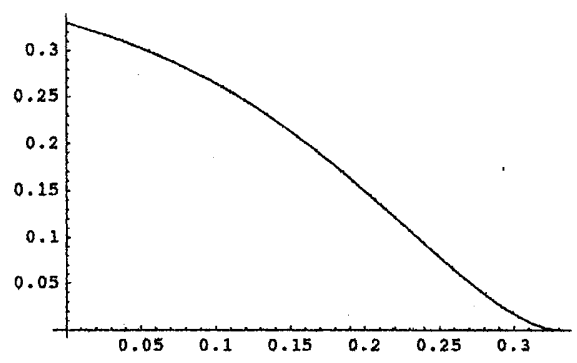

\section{Lemma 3.2}

P1xiand2 $\left[a_{-}, c_{-}\right]:=\frac{a(6-2 c)}{41-66 c+21 c^{2}}-P 1 \times 2$ then $\left[a_{-}, c_{-}\right]:=\frac{a\left(-29+18 c+15 c^{2}\right)}{12(1-c)\left(-17+18 c+3 c^{2}\right)}>0$

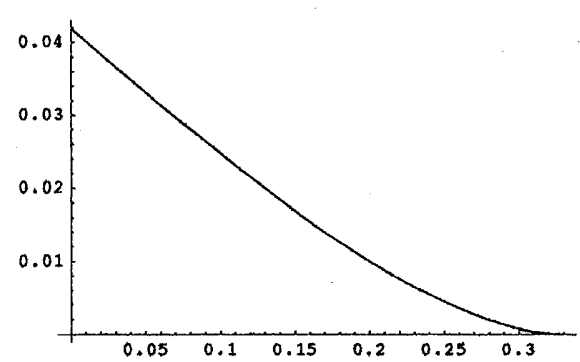

P2x1and2 [a_, c c] $:=\frac{4 a(3-c)}{41-66 c+21 c^{2}}-P 2 \times 2$ thend $\left[a_{-}, c_{-}\right]:=\frac{a\left(-29+18 c+15 c^{2}\right)}{6(1-c)\left(-17+18 c+3 c^{2}\right)}>0$

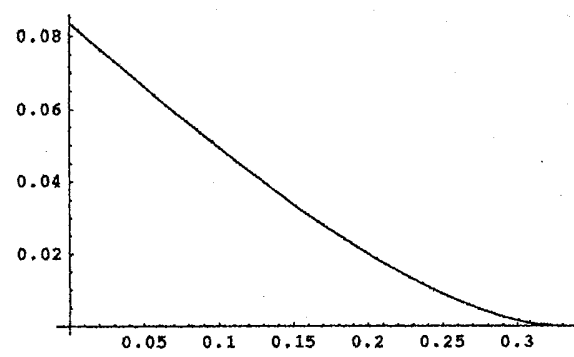


Q1x1and2[a_, $\left.a_{-}\right]:=\frac{a\left(7+14 c-9 c^{2}\right)}{(1-3 c)\left(41-66 c+21 c^{2}\right)}-01 \times 2 \operatorname{then} 1\left[a_{-}, c_{-}\right]:=-\frac{a\left(34+39 c-51 c^{2}+4(-5+3 c)+9 \sigma^{2}(-5+3 c)\right)}{6\left(1-4 c+3 c^{2}\right)\left(-17+18 c+3 c^{2}\right)}>0$

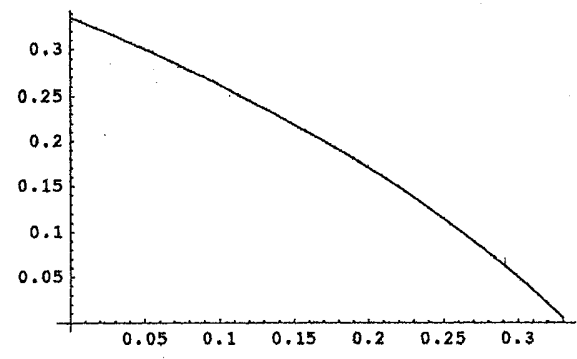

R1x1and2 $\left[a_{-}, c_{-}\right]:=\frac{2 a(5-3 c)}{1-66 c+21 c^{2}}-R 1 \times 2 \operatorname{then} 1\left[a_{-}, c_{-}\right]:=\frac{a(5-3 c)}{17-18 c-3 c^{2}}<0$

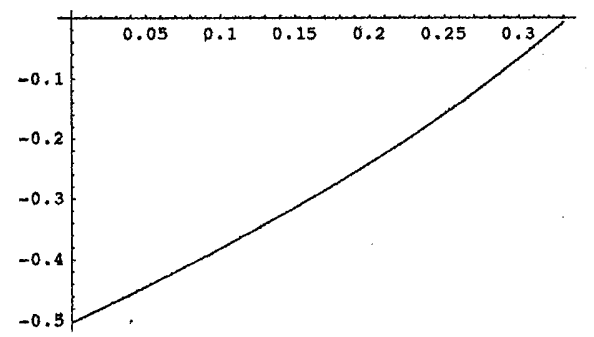

Lemma 3.3

P1x1then2 $\left[a_{-}, c_{-}\right]:=\frac{2 a\left(5-23 c+35 c^{2}-15 c^{3}-6 c^{4}\right)}{64-358 c+721 a^{2}-567 c^{3}+63 c^{4}+45 c^{5}}-p 1 \times 2 \operatorname{then} 1\left[a_{-}, c_{-}\right]:=\frac{a\left(-29+18 c+15 c^{2}\right)}{12(1-a)\left(-17+18 c+3 c^{2}\right)}>0$

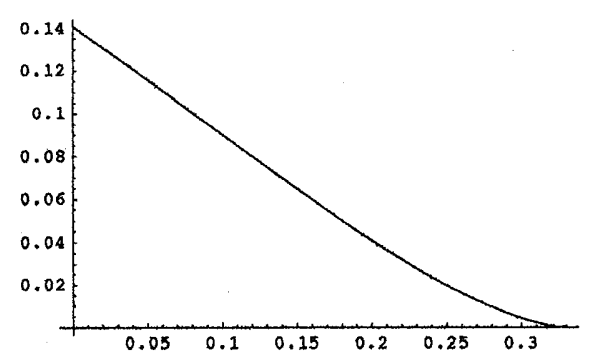

P2x1 then2 $\left[a_{-}, a_{-}\right]=\frac{4 a\left(5-23 c+35 c^{2}-15 c^{3}-6 c^{4}\right)}{64-358 c+721 c^{2}-567 c^{3}+63 c^{6}+45 c^{5}}-P 2 \times 2 \operatorname{tben} 1\left[a, c \ldots l=\frac{a\left(-29+18 c+15 c^{2}\right)}{6(1-c)\left(-17+18 c+3 a^{2}\right)}>0\right.$

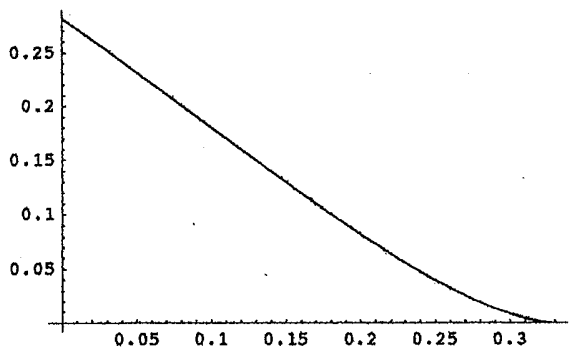

Q1xithen2 $\left[a_{-}, a_{-}\right]:=$

$\frac{a\left(13-38 c-18 c^{2}+162 c^{3}-159 c^{4}\right)}{\left(64-358 c+721 c^{2}-567 c^{3}+63 c^{4}+45 c^{5}\right)}-21 \times 2 \operatorname{then} 1\left[a_{-}, c_{-}\right]:=-\frac{a\left(34+39 a-51 c^{2}+4(-5+3 c)+9 c^{2}(-5+3 c)\right)}{6\left(1-4 c+3 c^{2}\right)\left(-17+18 c+3 c^{2}\right)}>0$

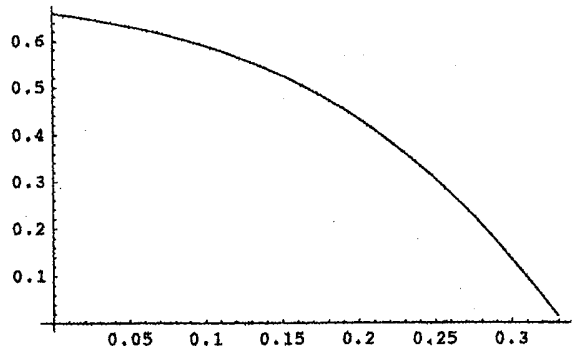


R1x1then2 $\left[a_{-}, a_{-}\right]: \pi \frac{a\left(-27+249 c-888 c^{2}+1542 c^{3}-1335 c^{4}+513 c^{5}-54 c^{6}\right)}{2(1-2 c)(-1+3 c)\left(64-358 c+721 c^{2}-567 c^{3}+63 c^{4}+45 c^{5}\right)}-R 1 \times 2 \operatorname{then} 1\left[a_{-}, c_{-}\right]:=\frac{a(5-3 c)}{17-18 c-3 c^{2}}<0$

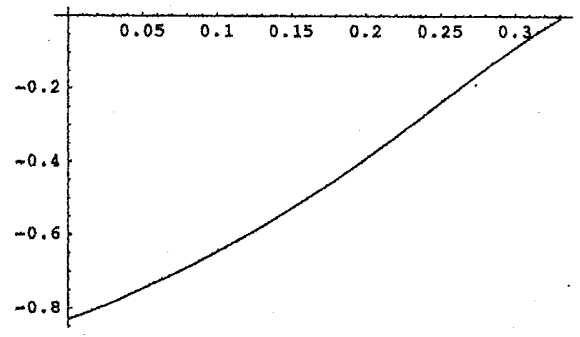

\section{Proposition3 . 1}

TD1and2W $\left[a_{-}, c_{-}\right]:=\frac{8 a(-3+c)(-5+3 c)}{41-66 c+21 c^{2}}-\operatorname{Tb} 1$ then2w $\left[a_{-}, c_{-}\right]:=\frac{4 a\left(9-20 c+3 a^{2}\right)\left(5-13 c+9 c^{2}+3 c^{3}\right)}{64-358 c+721 c^{2}-567 c^{3}+63 a^{4}+45 c^{5}}>0$

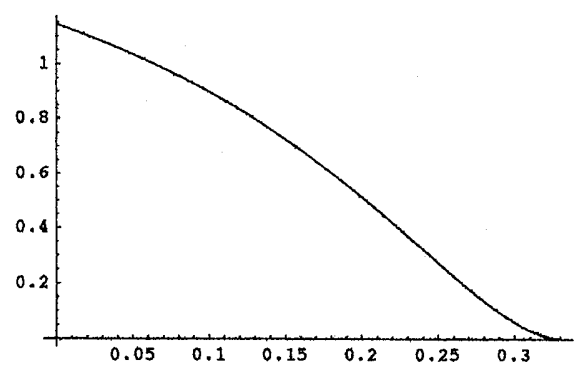

\section{Proposition3 . 2}

$\operatorname{TD} 1 \mathrm{and} 2 W[a, c]:=\frac{8 a(-3+c)(-5+3 c)}{41-66 c+21 c^{2}}-\operatorname{TD2then} 1 w\left[a_{-}, a_{-}\right]:=-\frac{a(5-3 c)\left(29-18 c-15 c^{2}\right)}{3(1-c)\left(-17+18 a+3 a^{2}\right)}>0$

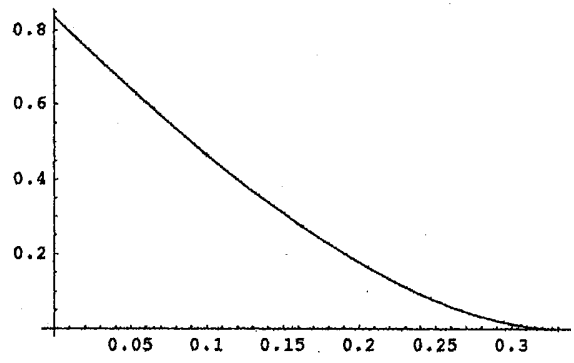

\section{Proposition 3 . 3}

TDIthen2w[a, $c]:=\frac{4 a\left(9-20 c+3 c^{2}\right)\left(5-13 c+9 c^{2}+3 c^{3}\right)}{64-358 c+721 c^{2}-567 c^{3}+63 c^{4}+45 c^{3}}-\operatorname{TD} 2 \operatorname{then} 1 w[a, c]-\frac{a(5-3 c)\left(29-18 c-15 c^{2}\right)}{3(1-c)\left(-17+18 c+3 c^{2}\right)}<0$

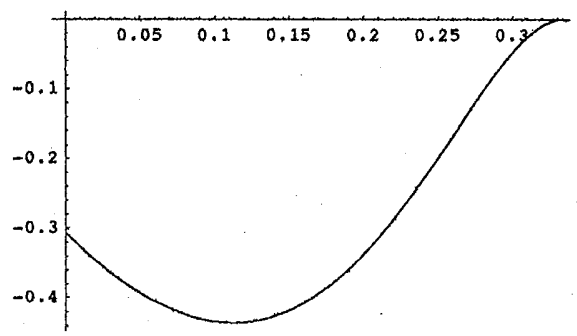

